\title{
LA VASCONIA DE MANUEL RISCO Y LA POLÉMICA SUBSIGUIENTE SOBRE EL PASADO DE NAVARRA
}

\author{
POR \\ FERNANDO MIKELARENA PEÑA \\ Universidad de Zaragoza. Departamento de Ciencias de la \\ Documentación e Historia de la Ciencia
}

\section{RESUMEN}

La publicación de La Vasconia, volumen XXXII de la colección España Sagrada, de Manuel Risco generó una polémica sobre los orígenes del reino de Navarra. Sus contenidos se pueden relacionar con las ideas sobre la historia de Navarra que sostenía Campomanes. En esa polémica participaron Juan Antonio Fernández y Miguel de Hualde, que no consiguieron el apoyo de la Diputación. La obra de Risco tendría ecos en la aportación realizada sobre Navarra por Traggia en 1802 editada en el Diccionario de la Real Academia de la Historia.

PALABRAS CLAVE

España Sagrada; Manuel Risco; Historia de Navarra.

\section{LA VASCONIA OF MANUEL DE RISCO AND THE SUBSEQUENT CONTROVERSY OVER THE PAST OF NAVARRA}

\section{ABSTRACT}

The publication of La Vasconia, Volume XXXII from the España Sagrada collection, by Manuel Risco generated a controversy about the origins of the kingdom of Navarre. Its contents may be related with ideas about the history of Navarre held by Campomanes. In this controversy took part Juan Antonio Fernandez and Miguel de Hualde, who did not get the support of the navarre Diputation. Risco's work would have echoes in the contribution about Navarre made by Traggia in 1802 published in the Dictionary of the Royal Academy of History. 


\section{KEY WORDS}

España Sagrada; Manuel Risco; History of Navarre.

$\begin{array}{ll}\text { Recibido/Received } & 18-05-2010 \\ \text { Aceptado/Accepted } & 12-05-2014\end{array}$

En este artículo se analiza la polémica suscitada en Navarra por la publicación de La Vasconia, volumen XXXII de la colección España Sagrada, de Manuel Risco. Primeramente, de manera previa, y con el propósito de contextualizar el debate en una dinámica más amplia y general, se repasan los contenidos básicos de los discursos historiográficos principales sobre el pasado de Navarra de la Baja Edad Media y de la Edad Moderna acerca del origen del reino de Navarra y se alude a la posibilidad de que Campomanes inspirara los proyectos de Risco y Traggia a los que luego se menciona. Dada su influencia en el plano historiográfico como director de la Real Academia de la Historia y teniendo en cuenta sus respuestas como fiscal del Consejo y Cámara de Castilla a las representaciones de la Diputación navarra, al hilo de la cuestión de las quintas entre 1772 y 1773.

En segundo lugar, se estudian las tesis centrales de la obra de Risco y su carácter de refutación de los contenidos primordiales defendidos por los historiadores navarros en torno al surgimiento de la monarquía navarra, una cuestión hasta ahora no puesta de relieve por la historiografía.

En tercer lugar, se profundiza en la reacción generada en Navarra: la propuesta de Juan Antonio Fernández, erudito tudelano al que cabría calificar como el mejor historiador navarro de la segunda mitad del siglo XVIII, y los manuscritos redactados por Miguel de Hualde, una persona hasta entonces entregada a otros menesteres.

Como se verá, los ofrecimientos de uno y de otro serán desechados por las autoridades navarras. El del primero porque la Diputación responderá con un silencio negativo, y el del segundo, porque la evaluación de un texto encargada al monje benedictino de Leire Francisco de Arbeloa será desfavorable y ulteriores proposiciones relativas a otros escritos tampoco encontrarán eco.

En cuarto y último lugar se examina la influencia de Risco en Traggia, autor de la voz dedicada a Navarra publicada en los tomos 
centrados en dicho reino y en las provincias vascongadas, los únicos editados, del Diccionario geográfico-histórico de España de la Real Academia de la Historia de 1802.

\section{LOS DISCURSOS SOBRE EL PASADO DE NAVARRA DURANTE LA EDAD MODERNA.}

Dos grandes tipos de discursos historiográficos se enfrentan en relación con Navarra a lo largo de la Baja Edad Media y de la Edad Moderna. Uno, elaborado desde Castilla, y otro, elaborado desde Navarra, proporcionan versiones diferentes del origen de Navarra y de la relación entre rey y reino, correspondiéndose con culturas políticas asimismo disímiles.

Esos discursos enfrentan soberanía absoluta de los reyes con fuerismo o poder limitado de aquéllos, particularismo navarro con castellano-centrismo. Un discurso servía al afán asimilador del poder central castellano a partir de la refutación de los elementos de diferenciación del reino navarro, poniéndolo bajo la dependencia de las monarquías antecesoras del reino castellano y remarcando la soberanía sin cortapisas de los reyes absolutos de la monarquía hispánica de la Edad Moderna. El otro discurso servía a quienes querían subrayar que, tras 1512, Navarra era un reino diferenciado de Castilla, insistiendo en el carácter de principalidad de la unión del reino navarro con el castellano después de aquella fecha, fundamentándose en un concepto de soberanía limitada de la autoridad regia a causa de la obligación de ésta de contar con el consenso de las Cortes navarras. ${ }^{1}$ No hay que olvidar la función política de los discursos historiográficos como "un elemento central del orden jurídico premoderno" al gozar "en aquellas sociedades de una clara función constitutiva de derechos y obligaciones". ${ }^{2}$

El discurso castellanista encontraba su raíz en la Crónica gótica o Rerum in Hispania Gestarum Chronicon del arzobispo de Toledo, nacido precisamente en la localidad navarra de Puentelarreina, Rodrigo Jiménez de Rada (1170-1247). Esta obra, redactada hacia 1240, editada en 1545, 1603 y 1793, tuvo importante difusión entre los círculos eruditos. ${ }^{3}$ Para este autor, el reino de Navarra tenía una legitimidad espuria, residiendo la única y estricta legitimidad en la monarquía castellanoleonesa.

${ }^{1}$ Floristán Imízcoz, A. 1998. "Reflexiones sobre una identidad nacional a mediados del siglo XVI. Los orígenes del reino de Navarra", en Mito y realidad en la Historia de Navarra. Actas del IV Congreso de Historia de Navarra: 31-32 y 41-42. Pamplona: Sociedad de Estudios Históricos de Navarra, Volumen II.

${ }^{2}$ García Pérez, R. D. 2008. Antes leyes que reyes. Cultura jurídica y constitución política en la Edad Moderna (Navarra, 1512-1808): 170-171. Milano: Giuffrè Editore.

${ }^{3}$ Floristán Imízcoz, A. 1998: 31. 
Al ubicarse la fuente incontestable de la legitimidad del poder político en la monarquía visigótica, los reyes de Castilla y León engarzaban con aquélla a través de la monarquía asturiana de Don Pelayo, entendida ésta como continuidad de aquélla. En dicha crónica se presenta al primer rey navarro, denominado Enecho (Eneco) Arista, como posterior en el tiempo a Don Pelayo, carente de sangre real goda y ni siquiera español, imputándosele proceder del condado francés de Bigorra. ${ }^{4}$

Esas tesis historiográficas se trasladaron al terreno de la doctrina política. Dos destacados hombres de leyes castellanos del siglo XVI, ambos jueces del Consejo de Castilla, uno del principio de la centuria y otro del final, presentaron, amparados en aquellas tesis, a los reyes navarros vencidos en 1512 como usurpadores de la Corona y a los reyes castellanos, en un caso Fernando el Católico y en el otro Felipe II, como los legítimos derechos navarros dado su entronque con el trono instaurado por Don Pelayo. ${ }^{5}$

El primero, Juan López de Palacios Rubios, letrado del Consejo de Castilla y autor hacia 1516 de la obra De iustitia et iure obtentionis ac retentionis regni Navarre, obra de encargo para justificar la conquista de Navarra, indicó no sólo que Fernando el Católico había restaurado "la unidad gótica, de la que Navarra se había separado injustamente al elegir por rey a Iñigo Arista", sino que además dio por cierto que tanto reyes visigodos como sucesores de Don Pelayo habían reinado en estas tierras, truncándose su dominio tras una ofensiva de los musulmanes y tras la victoria sobre éstos de Iñigo Arista, proveniente del condado de Bigorra y autoproclamado rey de los navarros.

Al ser los reyes de Navarra solamente reyes de hecho, pero no de derecho, eran, pues, los reyes de Castilla los únicos detentadores de la legitimidad visigoda. ${ }^{6}$ Palacios Rubios afirmaba que Dios, en un acto providencial, había devuelto la corona de Navarra a sus legítimos poseedores, los reyes castellanos, estableciendo "una continuidad perfecta" entre los visigodos, Don Pelayo, el reino de Castilla y León, continuidad "que hace extensiva a Fernando el Católico".

${ }^{4}$ Ibidem: 32-33.

${ }^{5}$ Ibidem: 30.

${ }^{6}$ Leoné Puncel, S. 2005. Los Fueros de Navarra como lugar de la memoria: 59. San Sebastián: Fundación para el Estudio del Derecho Histórico y Autonómico de Vasconia.

7 Floristán Imízcoz, A. 1999. "¿Conquista o restauración?. La incorporación de Navarra a la monarquía española”, Hispania LIX/2: 470-471. 


\section{LA VASCONIA DE MANUEL RISCO Y LA POLÉMICA SUBSIGUIENTE 301 SOBRE EL PASADO DE NAVARRA}

El segundo autor, Gregorio López Madera, en su obra Excelencias de la Monarchia y reino de España, publicada en Valladolid en 1597, reitera que Don Pelayo y sus sucesores son los únicos reyes legítimos de España, siendo meros usurpadores los reyes de Navarra y de Aragón. ${ }^{8}$

Por su parte, la génesis de las tesis particularistas navarras también data, al igual que sucedía con la crónica de Jiménez de Rada, de antes de la conquista de Navarra por Castilla. La Crónica de los Reyes de Navarra del Príncipe Carlos de Viana, escrita hacia 1454, tuvo una gran circulación por medio de copias manuscritas, dada la positiva reputación de su presunto autor como humanista. Las aportaciones de esta crónica son varias. En primer lugar, reivindica el origen propio de la realeza aragonesa y navarra, contemplando ésta como no subordinada a Castilla y con plena legitimidad por sus relaciones con dinastías godas y francesas. En segundo lugar, la monarquía navarroaragonesa, fue erigida libre y conscientemente por la comunidad respectiva, que había vivido varias décadas sin jerarquías reales, por medio de un pacto escrito (los fueros) en el que se señalaban unas condiciones. En tercer lugar, este texto proporciona detalles específicos de la figura del primer rey navarro, Iñigo Arista, especificando su origen noble como hijo del Señor de Abárzuza y de Viguria, y añadiendo a sus dotes militares otras capacidades, habitualmente predicadas de líderes similares, que acrecentaban su ascendencia sobre sus súbditos. ${ }^{9}$

Sancho de Alvear en su Genealogía de los Reyes de Navarra, obra escrita en 1507, polemiza con cronistas aragoneses del siglo XV como Pedro Tomic o Gauberto Fabricio de Vagad. En contra del Príncipe de Viana, ubica el surgimiento de la monarquía pirenaica en tierras navarras, desde donde habría tenido lugar después la conquista del Sobrarbe y de la Ribagorza. Iñigo Arista habría sido el quinto monarca de una secuencia iniciada con la coronación de García Jiménez, pero fue aquél quien juró los fueros y asumió el título de rey de Navarra. Aunque por su origen, como Señor de Abárzuza y de Viguria, era plenamente autóctono, fue, por casamiento, conde de Bigorra en Francia. ${ }^{10}$

La Crónica de los muy excelentes reyes de Navarra de Diego Ramírez Ávalos de la Piscina, escrita hacia 1534, posterior, por lo tanto, a la conquista, circuló abundantemente también mediante copias manuscritas. ${ }^{11}$ En ella, los navarros, enmarcados en reino, y los aragoneses, articulados como condado dependiente de aquél, participan de la elección de García Jiménez como primer rey. Seis reyes después,

\footnotetext{
${ }^{8}$ Leoné Puncel, S. 2005: 104.

${ }^{9}$ Floristán Imízcoz, A. 1998: 30-36.

${ }^{10}$ Leoné Puncel, S. 2005: 52-53.

${ }^{11}$ Floristán Imízcoz, A. 1998: 31.
} 
fue coronado Iñigo Arista rey de Pamplona, Sobrarbe y Ribagorza. De él se dice que era natural de las Améscoas y de Abárzuza y que tenía sangre goda por su parentesco con los duques de Cantabria y con los condes de Bigorra.

Llegados a este punto, Ávalos de la Piscina introduce un detalle importantísimo: la elección de Arista fue resultado de la decisión consensuada en torno a su persona, tras muchos intentos fallidos, de doce varones ricoshombres, elegidos por el rey precedente en su lecho de muerte, que gobernaron el reino durante más de cuatro decenios, llegando a ejercer una autoridad tan grande que, desde entonces, quedó asentada su preeminencia sobre el mismo monarca. Tal y como señalaba el Príncipe de Viana, esos doce pares habrían obligado a Arista a jurar los fueros de Navarra. ${ }^{12}$

La antigüedad del reino y su legitimidad goda, análoga a los del reino asturiano, y la insistencia en la importancia de los ricoshombres frente al rey son argumentos nucleares para articular una visión desde Navarra de la inserción de este reino en la monarquía hispánica, remarcando la imagen de una entidad político-institucional, con derecho propio de gobierno coparticipado entre rey y Cortes. ${ }^{13}$

Ávalos de la Piscina refuta a López de Palacios Rubios equiparando la antigüedad del reino navarro con la del asturiano, negando la dominación de éste sobre aquél y apoyando su naturaleza gótica, y subraya la obligación de los reyes castellanos de jurar los fueros.

La Sumaria relación de los apellidos del licenciado Reta, una obra inédita de la segunda mitad del siglo XVII, introduce un elemento nuevo al enfatizar que el reino de Navarra era anterior a los de Castilla y Aragón, tan antiguo como el asturiano y sugiriendo incluso que Don Pelayo era de origen navarro, y al fundamentar la legitimidad de la dinastía real navarra como la dinastía de los primitivos españoles. ${ }^{15}$

Los cronistas navarros del siglo XVII reforzarán los argumentos anteriores con otros tendentes a resaltar todavía más la originalidad de Navarra con otros razonamientos, tomados del vascocantabrismo y del tubalismo, mito defendido inicialmente por historiadores vizcaínos y

12 Ibidem: 37-40.

${ }^{13}$ Leoné Puncel, S. 2005: 56-57.

14 Ibidem: 56-61.

15 Floristán Imízcoz, A. 1999. Lealtad y patriotismo tras la conquista de Navarra. El licenciado Reta y la "Sumaria relación de los apellidos". Pamplona: Gobierno de Navarra. 


\section{LA VASCONIA DE MANUEL RISCO Y LA POLÉMICA SUBSIGUIENTE 303 SOBRE EL PASADO DE NAVARRA}

guipuzcoanos del siglo XVI como Poza, Martínez de Zaldibia o Garibay, ${ }^{16}$ autores, que, desde el primer momento, no dudaron en incluir a Navarra dentro de la Cantabria que reivindicaban para las Provincias Vascongadas. ${ }^{17}$

Ese proceso es llamativo en la medida en que, si bien en las Provincias Vascongadas el mito tubalista era necesario como fundamento último de legitimación de algunas construcciones sociopolíticas como los estatutos colectivos de hidalguía y del mismo régimen foral, Navarra presentaba un nivel de desarrollo y solidez institucional muy superior al de aquellos territorios, pues contaba "desde antiguo de una ley fundamental del reino, con artículos orgánicos que prevén disposiciones específicas en materia de ejercicio de los poderes públicos y de funcionamiento de las instituciones políticas". ${ }^{18}$

En rigor, en Navarra el vascocantabrismo solamente tendría sentido en las zonas de la Montaña, que gozaban de ejecutorias de hidalguía colectiva, similares a las que regían en toda Guipúzcoa y Vizcaya, que permitían a sus habitantes regular el equilibrio poblaciónrecursos y exportar de la mejor manera posible el excedente humano, favoreciendo de paso a una parte de aquéllos, a las oligarquías vecinales, en unos sitios más amplias que en otros.

La circunstancia de que Navarra, tras 1512, continuara "todavía ofreciendo a sus élites dirigentes un estatuto y un marco de actuación claramente definidos y privilegiados, por cuya conquista no habrán de pelear, como sus congéneres de las Vascongadas, mezclándose en

${ }^{16}$ Sobre vascocantabrismo y tubalismo, veánse Mañaricua, A. E. 1971. Historiografía de Vizcaya (desde Lope García de Salazar a Labayru). Bilbao: La Gran Enciclopedia Vasca; Caro Baroja, J. 1972. Los vascos y la historia a través de Garibay (Ensayo de biografía antropológica). San Sebastián: Txertoa; Otazu, A. 1973. El igualitarismo vasco: mito y realidad. San Sebastián: Txertoa; Fernández Albadalejo, P. 1975. La crisis del Antiguo Régimen en Guipúzcoa. Cambio económico e Historia, 1766-1833. Madrid: Akal; Tovar, A. 1980. Mitología e ideología sobre la lengua vasca. Historia de los estudios sobre ella. Madrid: Alianza; Aranzadi, J. 1981. Milenarismo vasco. Edad de oro, etnia y nativismo. Madrid: Taurus; Juaristi, J. 1992, Vestigios de Babel. Para una arqueología de los nacionalismos españoles. Madrid: Siglo XXI; Martínez Gorriarán, C. 1993. Casa, provincia, rey (Para una historia de la cultura del poder en el País Vasco). Ensayo. San Sebastián: Alberdania; Goyhenetche, J. 1993. Les basques et leur histoire. Mythes et realités. Bayona-Donostia: Elkar; Madariaga Orbea, J. 2008. Apologistas y detractores de la lengua vasca. San Sebastián: Fundación para el Estudio del Derecho Histórico y Autonómico de Vasconia.

17 Larrañaga Elorza, K. 1998. "Cantabrismo en Navarra". Príncipe de Viana 214: 455.

18 Ibidem: 473 y 478. 
tratos con las clases subordinadas y, si es preciso, transigiendo con ellas", hacía que aquéllas se debieran haber sentido menos proclives que las de Vascongadas "a comulgar con mitos ennoblecedores como el de Túbal o el vascocántabro, mitos que, si sirven a preservar un espacio de poder local o regional, lo hacen a costa de rebajar las preeminencias del grupo dirigente propiamente dicho dentro de una masa universalmente hidalga". ${ }^{19}$

En la Historia apologética, y descripción del Reino de Navarra, publicada por Juan de Sada y Amézqueta en 1628, bajo el seudónimo de García de Góngora y Torreblanca, primera historia de Navarra escrita por un navarro que se imprimió, se inicia una polémica con historiadores aragoneses acerca de la mayor antigüedad del reino navarro sobre la del aragonés de la que se harán eco también Moret y otros. ${ }^{20}$ Con todo, mucho más importante para nuestros fines, son los efectos ideológicos y políticos de las argumentaciones basadas en el cantabrismo y en el tubalismo.

Sada y Amézqueta apunta que los godos eran extranjeros que invadieron España tiranizando a los primitivos españoles descendientes de Túbal en un dominio claramente usurpador del que es imposible derivar ninguna legitimidad dinástica al modo como lo hacían los defensores de la tesis asturianista. Por lo tanto, al ser los navarros genuinos descendientes de Túbal y de los primitivos pobladores, el reino de Navarra contaba con más legitimidad que el asturiano ( $y$ por extensión, que el castellano), asentados en la continuidad de la inicialmente usurpadora dinastía visigótica.

En relación con la conquista, Sada y Amézqueta afirma que el juramento inicial del primer rey navarro de respeto a los fueros mediante contrato recíproco con la comunidad, también incumbe a los reyes de Castilla tras 1512. Para reforzar este punto, discierne la actitud del reino de la del rey depuesto, Juan de Albret, señalando que la legitimidad de la guerra contra éste por cismático no tenía por qué afectar a aquél, máxime cuando Navarra se entregó por su propia voluntad bajo la consideración de la promesa de Fernando el Católico de conservar los

19 Ibidem: 478.

${ }^{20}$ Sobre la polémica entre autores navarros y aragoneses pueden leerse Floristán Imízcoz, A. 2004. "Ex hostibus et in hostes. La configuración de las identidades colectivas como confrontación múltiple: Navarra entre Sobrarbe y Cantabria (siglos XVII y XVIII)", en García García, B. J. y Álvarez-Ossorio Alvarino, A., coords., La monarquía de las naciones: patria, nación y naturaleza en la monarquía de Espana. Madrid: Fundación Carlos de Amberes, pp. 327354; Jimeno Aranguren, R. 2011. "Pedro Abarca y su tratado manuscrito $<<$ Origen y progresos de la contienda sobre los primeros reyes de Aragón y Navarra , llamados de Sobrarbe>> (c. 1685)", Pedralbes, 31: 91-123. 


\section{LA VASCONIA DE MANUEL RISCO Y LA POLÉMICA SUBSIGUIENTE 305 SOBRE EL PASADO DE NAVARRA}

fueros. ${ }^{21}$

El tudelano Pedro de Agramont y Zaldívar, autor de una Historia de Navarra finalizada hacia 1632, participa del empeño cántabro-tubalista de Sada y Amézqueta en presentar a los reyes de Navarra como descendientes de los originarios españoles y como de estirpe más noble que la de los monarcas visigodos. Valora positivamente la conquista de Navarra por las tropas de Fernando el Católico a cuenta de los beneficios obtenidos por el reino navarro de tal hecho, por efecto de la falta de enfrentamientos bélicos en su suelo y de las oportunidades ofrecidas a sus élites al servicio del imperio español. Ello es compatible con su insistencia en presentar a Navarra como el reino más antiguo de España y como el origen de la reconquista, así como con su recuerdo a los reyes castellanos de la necesidad de observar la foralidad navarra para la renovación del pacto originario, tal y como hacían los monarcas navarros antes de 1512, y de su obligación de contar con las Cortes navarras. ${ }^{22}$

Todos los extremos apuntados por los autores anteriores conocen su formulación más depurada en la obra del primer cronista oficial del reino, y mejor historiador navarro de la época moderna cabría decir, el jesuita pamplonés José de Moret (1615-1687), designado para el cargo en 1654, un siglo más tarde del surgimiento de tal figura en Aragón. Su profunda erudición le permite sortear las críticas del suletino Oihenart al mito cántabro-tubalista y seguir explotando sus rentables aspectos en el ámbito de lo político-jurídico-institucional, hasta creer que "los reyes de España tienen una ascendencia más insigne por la línea de los reyes de Navarra, originarios españoles, descendientes de Túbal, que por la de los reyes de Asturias, godos, bárbaros advenedizos".

Moret da un paso más, al considerar que con el Fuero General, ordenado bajo Teobaldo I, los vascones navarros concretaron sus "leyes fundamentales y forma de gobierno" previamente a la elección del primer rey, leyes fundamentales conservadas desde entonces por medio de los juramentos renovados efectuados al reino por cada monarca y situadas por encima del propio rey, que no podía abolirlas. Por último, Moret blinda las leyes fundamentales como elemento que contribuye a particularizar el reino dentro de la Monarquía hispánica con dos argumentos añadidos relativos al compromiso del primer rey, y de los siguientes, a <<amejorar >> los fueros $<<y$ no empeorarlos $>>$ y a la imposibilidad para el monarca de hacer $<<$ hecho granado $>>$ alguno sin el consenso del Consejo de los doce ricoshombres, identificables en la edad moderna con los tres Estados. ${ }^{23}$

\footnotetext{
${ }^{21}$ Leoné Puncel, S. 2005: 105-109.

22 Ibidem: 118-121.

${ }^{23}$ Ibidem: 125-151.
} 
LAS CONSIDERACIONES DE CAMPOMANES ACERCA DE LA HISTORIA DE NAVARRA AL HILO DE LA POLÉMICA SOBRE LAS QUINTAS DE 1772-1777.

Pedro Rodriguez Campomanes (1723-1802) ocupó la fiscalía del Consejo de Castilla desde 1762, así como la de la Cámara de Castilla desde 1767, hasta 1783, fecha de su toma de posesión de la plaza de consejero y camarista de Castilla. ${ }^{24}$ Entre 1783 y 1789 ejerció como Decano Gobernador interino del Consejo de Castilla, siendo desde la segunda fecha y hasta 1791 Decano Gobernador del mismo en propiedad. En 1791 se incorporó al Consejo de Estado. Por otra parte, hay que destacar que formó parte de la Real Academia de la Historia desde 1748, presidiéndola entre 1764 y 1791 y entre 1798 y $1801 .{ }^{25}$

Dentro del Consejo de Castilla, la fiscalía tenía una gran importancia. Situados en un status inmediatamente inferior al de los consejeros, pero sin derecho a voto, los fiscales, dos hasta 1769, y tres a partir de entonces, representaban los intereses del monarca y del público, informaban al Consejo en asuntos gubernativos, en los legislativos y en muchos de los contenciosos, y eran quienes elaboraban, a partir del análisis de los casos y reclamaciones que llegaban al Consejo, las propuestas normativas que, de contar con el beneplácito de tal órgano y con la venia real, podían convertirse en leyes. También examinaban las propuestas legislativas enviadas por el rey, defendiéndolas ante el Consejo. ${ }^{26}$ Por todo ello, eran la piedra angular de la organización y funcionamiento del Consejo Real de Castilla. ${ }^{27}$

Campomanes fue el autor en buena medida de las reformas

${ }^{24}$ En el siglo XVIII, el Consejo de Castilla se mantenía todavía, no obstante la interferencia de las Secretarías de Estado y del Despacho con la llegada de los Borbones, como el órgano máximo de gobierno interior con amplísimas y heterogéneas competencias, casi sobre todas las materias, y como el tribunal supremo de justicia (tanto administrativa como civil y criminal). Además, teniendo en cuenta la ausencia de Cortes en Castilla, era un órgano de gran protagonismo en lo tocante a la iniciativa legal ya que no sólo legitimaba las leyes confeccionadas en los ministerios, sino que podía elaborar propuestas con criterios autónomos que podían convertirse en leyes, necesitando siempre el visto bueno final del rey. Cfr. De Castro, C. 1996. Campomanes. Estado y reformismo ilustrado: 15-16. Madrid: Alianza; Llombart, V. 1992. Campomanes, Economista y político de Carlos III: 99-100. Madrid: Alianza Universidad.

25 Vallejo García-Hevia, J. M. 1997. La monarquía y un ministro, Campomanes: 21-45. Madrid: Centro de Estudios Políticos y Constitucionales.

${ }^{26}$ De Castro, C. 1996: 16.

${ }^{27}$ Vallejo García-Hevia, J. M. 1997: 54-55. 


\section{LA VASCONIA DE MANUEL RISCO Y LA POLÉMICA SUBSIGUIENTE 307 SOBRE EL PASADO DE NAVARRA}

emprendidas durante el reinado de Carlos III desde su papel de fiscal del Consejo y Cámara de Castilla a través de sus dictámenes y alegaciones. ${ }^{28}$ Su papel excedió el de mero fiscal a causa de varios factores como su larga permanencia en el cargo, mientras numerosas personas rotaban en los puestos de máxima responsabilidad; ${ }^{29}$ su fuerte y perseverante personalidad en un entramado administrativo caracterizado por la indefinición competencial y la falta de coordinación en la administración; ${ }^{30}$ y sus fluidas relaciones con la mayoría de los ministros y secretarios de Estado. ${ }^{31}$

Su labor se vio facilitada por su enorme capacidad intelectual y de trabajo y por su amplia formación en derecho, en historia y en muchas disciplinas más. ${ }^{32}$ No olvidemos que dirigió la Academia de la Historia durante treinta años y presidió la Academia de Jurisprudencia. Asimismo, impulsó la creación de las Sociedades Económicas de Amigos del País y perteneció a numerosas academias y sociedades literarias o científicas, españolas y extranjeras. ${ }^{33}$ Considerando solamente sus obras editadas 0 conservadas en manuscrito, se le ha calificado como "uno de los escritores más prolíficos e influyentes del siglo, especialmente en materias económicas y políticas", ${ }^{34}$ pero también sobre educación, geografía y agronomía. ${ }^{35}$ Además, demostró ser como fiscal un escritor incansable en la elaboración de dictámenes sobre las más variadas materias de gobierno y administración. ${ }^{36}$

Desde su fiscalía, Campomanes intervino activamente en un amplio elenco de asuntos. En lo económico tuvo una importante participación en la liberalización del comercio colonial, la libertad de comercio de granos, la repoblación de Sierra Morena, el proceso de ley agraria, la reforma de los gremios y la de los oficios, las cuestiones hacendísticas, etc. Fue un importante defensor de los derechos de la monarquía contra la Iglesia y las órdenes religiosas. Fue quien impulsó la causa contra la Compañía de Jesús acusándola de ser la instigadora del motín contra Esquilache. ${ }^{37}$ Su frenesí reformador también se aplicó a la administración local, a los centros de enseñanza y a las universidades, a

${ }^{28}$ Coronas González, S. M. 2002. "Estudio Preliminar", en P. Rodriguez Campomanes, Inéditos políticos: p. XI. Oviedo: Junta General del Principado de Asturias.

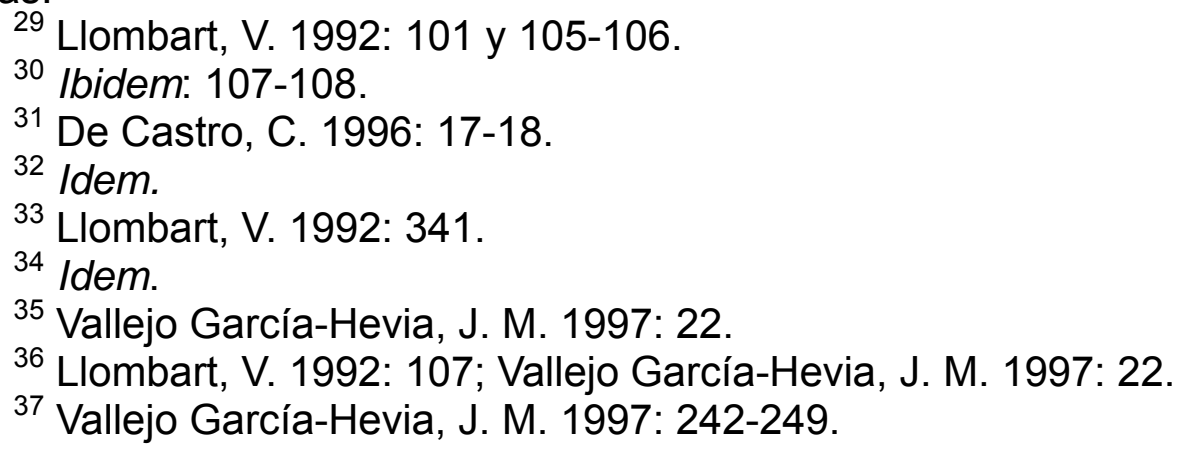


la política cultural y al mercado de libros, a las diversiones públicas, a la reforma de la beneficencia, a la creación de las Sociedades Económicas, a las quintas y a la incorporación de señoríos a la corona. ${ }^{38}$

En relación con Navarra, Campomanes elaboró, al hilo de la polémica sobre las quintas, los ejes argumentales del discurso historiográfico y jurídico, que, posteriormente, desarrollarían historiadores como Risco y como Traggia, y cuyo objetivo era socavar la autonomía de dicho reino dentro de la monarquía hispánica.

Dicha polémica sobre quintas entre Navarra y el Estado giró en torno al intento por parte de Carlos III de implantar un sistema de reclutamiento obligatorio de cubrimiento anual para el reemplazo del ejército por medio de la Real Ordenanza de 3 de noviembre de 1770, insertada en una Real Cédula de 24 de noviembre. Las provincias de la antigua Corona de Aragón, el Reino de Navarra y las tres provincias vascongadas debatieron con el gobierno central sobre si la norma les alcanzaba ya que consideraban que "en virtud de sus fueros y privilegios, no estaban sujetas estrictamente al reemplazo anual, aunque sí estaban obligadas a aportar un número determinado de soldados cuando el monarca así lo ordenase" ${ }^{\prime 3}$. La discusión derivó asimismo hacia el alcance de la soberanía regia sobre esos territorios.

En el caso específico de Navarra la polémica fue realmente importante. A partir de 1772, dará lugar a largos memoriales cruzados entre la Diputación navarra y el Consejo de Castilla en los que, por primera vez, el reino se vió obligado a justificar desde el punto de vista teórico, empleando argumentos jurídicos y filosóficos de peso, su negativa a aceptar las reformas generales que se planteaban introducir desde Madrid, sobre todo porque así se le exigió desde la parte contraria, dada la altura a la que Campomanes condujo el debate y dados los objetivos que perseguía. ${ }^{40}$ La intención uniformizadora de Campomanes en relación con Navarra, el único territorio que en la segunda mitad del XVIII podía debatir con Castilla de reino a reino, se traslució a fechas tempranas. En 1753, al elaborar una Lista de los libros principales, que tratan del derecho público, y que deben adquirirse para una librería bien formada Campomanes recomendaba expresamente a los escritores como Solórzano Pereira y Palacios Rubio por mostrar $<<$ la soberanía de los Reyes de Castilla a las Islas Canarias y... al Reyno de Navarra>>",

${ }^{38}$ Llombart, V. 1992: 341-342; Vallejo García-Hevia, J. M. 1997: 242-254, $325-342$ y $388-415$.

39 Vallejo García-Hevia, J. M. 1997: 389-393.

40 Floristán Imízcoz, A. 1991. La Monarquía Española y el Gobierno del Reino de Navarra, 1512-1808: 224. Pamplona: Gobierno de Navarra; García Pérez, R. D. 2008: 189 y 205-206. La polémica también ha sido estudiada por Vallejo García-Hevia, J. M. 1997: 395-415 y Leoné Puncel, S. 2005: 167-192. 


\section{LA VASCONIA DE MANUEL RISCO Y LA POLÉMICA SUBSIGUIENTE 309 SOBRE EL PASADO DE NAVARRA}

aconsejando asimismo la lectura de las obras de Caramuel y Pellicer que mostraban lo propio respecto a Portugal y Cataluña. ${ }^{41}$

En el curso de esa polémica Campomanes realizó una aportación fundamental, el extenso informe que redactó a finales de diciembre de 1772 junto con el también fiscal Pedro González de Mena de 1772 en respuesta a una representación de la Diputación de Navarra presentada en mayo del mismo año. ${ }^{42}$ Más adelante, en 1777 Campomanes replicaría a otra representación de la corporación navarra, sintetizando los argumentos de cinco años atrás. ${ }^{43}$

Dejando de lado los argumentos jurídico-políticos, el principal argumento historiográfico apuntado por los dos fiscales en el informe de 1772 se dirigía a replicar la tesis manejada por la Diputación navarra relativo a que, desde la elección de García Ximénez por Rey en 716 hasta el año 1515, se habían observado "literalmente al Reyno de Navarra sus peculiares fueros, Leyes, usos y costumbres". Acerca de ello, los fiscales replican que Garcia Ximenez "entró en la posesión de este estado, no por elección de los Ricoshombres de Navarra" (en 857, no en 716), "sino como herencia de los Condes de Pamplona, sus antepasados que se avian establecido en aquel siglo, y eran feudatarios de los Reyes de Asturias, y de León" [Punto 69] y que "las Leyes de Navarra eran las mismas entonces que las generales de España" [Punto 70], por lo que se deduce que no podían ser "menores los derechos de los Reyes de Navarra en punto al levantamiento de tropas que los de otros Reyes de España, antes el mismo fuero los iguala en estas regalías" [Punto 71]. Asimismo, en referencia con el argumento de la Diputación acerca de que la incorporación de Navarra a Castilla había sido "principal y no accesoria", los fiscales responderán que "Esta alegación no parece conducente, por que no se trata de si la Corona de Navarra depende o no de la de Castilla; pero si se lee el capítulo de la

${ }^{41}$ Llombart, V. 1992: 72-73.

42 Archivo General de Navarra (AGN), Reino, Sección de Quintas y Levas, Legajo 1, Carpeta 18, Ynforme de los fiscales Don Pedro Rodriguez Campomanes y Don Pedro González de Mena acerca de la Representación de la Diputación de Navarra sobre la suspensión del establecimiento de la ordenanza del reemplazo del ejército. Rebaten las razones de la Diputación examinando y analizando la antigua soberanía de los Reyes de Navarra, la institución de la monarquía, los fueros y las condiciones y circunstancias con que se unió a Castilla (1772). Este dictamen fiscal también fue analizado por Vallejo García-Hevia, J. M. 1997: 409-412, así como por García Pérez, R. D. 2008: 208-215 y Leoné Puncel, S. 2005: 175-181.

${ }^{43}$ AGN, Reino, Quintas y levas, legajo 1, carpeta 36: Ynforme o censura dada a la Cámara de Castilla por el fiscal Don Pedro Rodriguez de Campomanes acerca de la representación de la Diputación del reino de 6 de septiembre de 1776 sobre el reemplazo del ejército (1777). 
unión echa en el año de 1515 según está en la noticia del cap. 17 lib. 34 de los Anales de Navarra se hallará que el Rey Cathólico don Fernando el 5 unió e incorporó el Reyno de Navarra a la Corona de Castilla aun que antes avía pensado a la de Aragón cuio acto original existe en el Real Archivo de Simancas; esta incorporación tiene más visos de ser accesoria, sin embargo de lo que expone la Diputación" [Punto 73].

Las tesis apuntadas por Campomanes acerca del origen y del carácter de la monarquía navarra en sus inicios, que tenían un fundamento en la historiografía castellana acerca de Navarra, conocerán una profunda elaboración por parte de Manuel Risco quien tratará de refutar los fundamentos últimos de las bases historiográficas navarristas que encontraron, como vimos, su cima en Moret.

\section{LA REINTERPRETACIÓN DEL PASADO DE NAVARRA DE MANUEL RISCO.}

Como es sabido, la colección España Sagrada. Teatro GeográficoHistórico de la Iglesia de España está constituida por un conjunto de monografías seriadas de historia eclesiástica española, dedicándose cada tomo a una zona específica. Este proyecto historiográfico fue diseñado por el historiador agustino Enrique Flórez a imitación de otras obras monumentales similares llevadas a cabo en otros países y es un clásico de la historiografía española que recogió un caudal importantísimo de documentos e informaciones. El propio Flórez preparó y publicó los 27 primeros volúmenes entre 1747 y 1773, contando con la ayuda real. A partir de 1773 la obra de Flórez fue continuada por uno de sus colaboradores, Manuel Risco, que tras editar en 1774 y 1775 los tomos XXVIII y XXXIX preparados por aquél, sería el responsable exclusivo de los volúmenes siguientes hasta el XLII. Otros autores como Merino y La Canal proseguirían la obra a lo largo del primer tercio del siglo XIX, y aún otros la continuarían en el ochocientos e incluso en el siglo $X X$.

El tomo 32 de la España Sagrada, obra de Manuel Risco y publicado en Madrid en 1779, tiene como título La Vasconia. Tratado preliminar a las santas iglesias de Calahorra, y de Pamplona: en que se establecen todas las antigüedades civiles concernientes a la región de los Vascones desde los tiempos primitivos hasta los Reyes primeros de Navarra.

Según figura en la biografía de Risco publicada en el prólogo al tomo XLIII dedicado al obispado de Gerona, Manuel Risco nació en Haro en 1735, llamándose en el siglo Juan Manuel Martínez Ugarte. Tomó el hábito agustino en 1752. Abandonó sus apellidos por el de Risco en homenaje al convento abulense en el que pasó la juventud. Tras estudiar 


\section{LA VASCONIA DE MANUEL RISCO Y LA POLÉMICA SUBSIGUIENTE 311 SOBRE EL PASADO DE NAVARRA}

teología en Salamanca, fue catedrático de esa disciplina en Valladolid entre 1765 y 1767. Ese último año pasó al Colegio de Doña María de Aragón de Madrid, donde llegaría a ser regente. Además de los trece tomos de la España Sagrada de los que fue responsable, Risco fue el autor de otras monografías de vindicación del Padre Flórez y relativas a la historia de los reinos de Castilla y de León. Falleció en $1801 .{ }^{44}$

La elaboración del tomo XXXII dedicado a Vasconia supuso para Risco un reto especial. No sólo es que, tal y como se señala en aquella biografía, su interés por "aclarar" los contenidos a los que se refirió "con más acierto que el que se había tenido en las descripciones de otros", además de a examinar "quanto estaba escrito", le moviera a "ver por sus ojos el terreno". ${ }^{45}$ También se aprecia una intencionalidad política clara, como veremos, en su reconstrucción del pasado de Navarra, connivente, además, con algunas de las ideas expresadas por Campomanes en la polémica mantenida con la Diputación navarra en relación con el asunto de las quintas. De hecho, en la misma biografía a la que nos estamos refiriendo se dice explícitamente que "el Gobierno Español aprobó y agradeció mucho este trabajo particular del Maestro Risco". ${ }^{46}$ No hay que olvidar, en relación con ello, el peso de Campomanes en la Real Academia de la Historia, además de en los cenáculos del poder. Con todo, tenemos que decir, que si bien la aportación de Traggia en relación con Navarra, de la que se hablará más tarde, ha merecido la atención de los historiadores, el tratamiento que Risco hacía del origen del reino navarro ha pasado desapercibido.

En el mismo prólogo de esa obra dedicada a Vasconia, Risco resume parte de los contenidos de la misma. En su opinión, el origen del Reino de Navarra es "objeto de los más enredosos y obscuros que pueden ofrecerse en la Historia" a causa del amor de los autores navarros y aragoneses "a su respectiva nación". "Los Navarros y Aragoneses modernos, como tan apasionados a las glorias de este Reyno, le atribuyen una antigüedad no menos remota que la adjudicada por todos los Historiadores a la dignidad Real instituída en Asturias", si bien "los mismos contienden luego con gran tenacidad y porfía sobre el establecimiento del Reyno, y sobre el título que gozaron primero sus Reyes". ${ }^{47}$ Bajo su punto de vista, "no se esclarecieron más los principios

44 Merino, A. y De la Canal, J. 1819. "Prólogo", en A. Merino y J. De la Canal, España Sagrada. Tomo XLIII. Tratado LXXXI de la Santa Iglesia de Gerona en su estado antiguo: XXIV-XXXI. Madrid: En la imprenta de Collado.

45 Ibidem: XXVIII.

46 Ibidem: XXIX.

47 Risco, M. 1779a. "Prólogo", en M. Risco, España Sagrada. Tomo XXXII. La Vasconia. Tratado preliminar a las santas iglesias de Calahorra, y de Pamplona: en que se establecen todas las antigüedades civiles concernientes a la región de los Vascones desde los tiempos primitivos hasta los Reyes 
del Reyno de Navarra en las obras del P. Moret" quien imputó a los cronistas anteriores, entre ellos a Zurita, "los vicios y achaques de ignorancia, escasez, y poca firmeza en las noticias". ${ }^{48}$ Risco no deja de mencionar que los esfuerzos de Moret "en prueba de que la dignidad Real de Navarra se instituyó en la parte de los Pyrineos que toca a este Reyno, y de que este suceso fue inmediato a la pérdida de España", ${ }^{49}$ han suscitado la crítica de algunos autores que "los han calificado de muy poco seguros, y de incapaces de mantener la fábrica que se erigió sobre ellos". ${ }^{50}$ Entre esos críticos Risco cita en las páginas siguientes a Mondéjar, Ferreras y Pellicer.

En su prólogo, Risco asume la responsabilidad de reexaminar la cuestión "separando lo verdadero de lo falso", asumiendo que "las pasiones diversas de los hombres, el deseo que todos tienen de que se escriba sólo aquello que les agrada", le obligaba "a desconfiar gravemente de que serán recibidos con general aceptación los dictámenes" que iba a sostener "acerca de la institución de la dignidad Real de Navarra", sobre todo, por poner de relieve "los fundamentos insubsistentes de que se han valido los modernos, a fin de exagerar la antigüedad del Reyno de Navarra, y de multiplicar sus Monarcas".

Risco anticipa, asimismo, en el preámbulo que ha demostrado que "es muy vana la gloria de los que han inventado una Cantabria invicta, o jamás vencida, no habiendo en la Costa septentrional parte tan retirada, o de tan firme resistencia, que no se rindiese al constante valor de los Romanos", indicando además que las zonas que van desde la Cantabria estricta a la frontera francesa "estubieron sujetas al Imperio mucho antes de la guerra Cantábrica". En este punto Risco sigue la línea de su maestro Enrique Flórez que en su obra La Cantabria, publicada por primera vez en $1768,{ }^{51}$ demostró la inconsistencia del mito cantabrista de los autores vascongados a través, sobre todo, de las informaciones de

primeros de Navarra: 3v. Madrid: En la imprenta de Miguel Escribano.

48 Ibidem: 4-4v.

49 Ibidem: 5.

50 Ibidem: 5v. A partir de aquí no recojo la página de las menciones que hago de este prólogo por no estar éste paginado.

${ }^{51}$ Flórez, E. 1768. La Cantabria. Disertación sobre el sitio, y extensión que tuvo en tiempo de los romanos la región de los Cántabros, con noticia de las Regiones confinantes, y de varias poblaciones antiguas: discurso preliminar al tomo XXIV de la España Sagrada sobre la provincia de la Tarraconense: Madrid, Por Antonio Marín. Posteriormete, la obra conocería una segunda edición, en formato independiente, en 1786. En el prólogo titulado Razón de este Tratado se dice que el motivo del libro surge "porque sin resolver donde estuvo" la antigua Cantabria "y quales fueron sus límites, o extensión; no es firme la aplicación a una u otra Provincia" y "hablando con términos más claros; sobre si fueron Cántabros los que hoy viven en las tres nobles Provincias de Álaba, Señorío y Guipúzcoa". 


\section{LA VASCONIA DE MANUEL RISCO Y LA POLÉMICA SUBSIGUIENTE 313 SOBRE EL PASADO DE NAVARRA}

los geógrafos e historiadores grecolatinos, eliminando, además, todo valor al mantenimiento del euskara como argumento a favor de la identificación de los territorios vascos con parte de la antigua Cantabria. Ese argumento, empleado desde el siglo XVI, pero en el que incidió especialmente en el siglo XVIII el jesuita Manuel de Larramendi, elevaba a aquel idioma a símbolo, privativo obviamente de los territorios vascohablantes, de la preservación en la Edad Moderna de la antigua actitud resistente cántabra. ${ }^{52} \mathrm{El}$ mismo año de la publicación de $\mathrm{La}$ Vasconia Risco ya había manejado los razonamientos de Flórez en su impugnación ${ }^{53}$ de la obra de José Hipólito de Ozaeta y Gallaiztegui titulada La Cantabria vindicada y demostrada, según la extensión que tuvo en diferentes tiempos, editada en Madrid también en 1779 y que era una refutación bastante pobre de la anterior obra de Flórez que trataba de demostrar la validez del cantabrismo para las provincias vascas.

Siguiendo con La Vasconia, Risco hace constar en ese prefacio un párrafo del que se desprende su consciencia del trasfondo político de su aportación, interpretándolo, además, de forma que no puede dejar de resultar chocante por lo aparatoso, en términos de confrontación historiográfica entre naciones, y posicionándose él mismo en el bando de la nación española. Ese párrafo dice lo siguiente: "Y aunque las sentencias, que sigo, son comúnmente gloriosas y favorables a España, de donde podría sobrevenir alguno en sospecha de mi sinceridad; pero tengo la satisfacción de que los testimonios y razones que propongo mostrarán con la mayor claridad, que el adherirme a ellas más ha sido efecto de inclinación a la verdad, que de amor ciego a la Nación".

Los contenidos de la obra de Risco se pueden resumir en dos grandes ejes. En primer lugar, refutación del tubalismo y del cantabrismo sostenido por los historiadores navarros y que servía para ignorar la significación positiva del goticismo. En segundo lugar, reivindicación del dominio visigótico y asturleonés sobre Vasconia y supeditación del reino navarro a los reyes asturianos y leoneses, acompañado de un desplazamiento en el tiempo hacia delante del origen de aquél como entidad política independiente, aunque no libre, incluso entonces, de su entronque por vía parental con dinastías visigodas y asturianas.

En el capítulo primero de su obra, titulado "Gentes que habitaron la Vasconia antes de la venida de los Cartagineses, y Romanos", Risco critica las tesis tubalistas de que los pobladores primitivos de España se habían establecido en Navarra, mencionando expresamente lo erróneo

${ }^{52}$ Larrañaga Elorza, K. 1998: 474.

53 Risco, M. 1779b. El R. P. M. Fr. Henrique Flórez vindicado del Vindicador de la Cantabria, Don Hipolyto de Ozaeta y Gallaiztegui. Madrid: En la Imprenta de Pedro Marín. 
de las posturas de Garibay, Henao y Moret. $^{54}$

Los otros aspectos quedan recogidos hacia el tercio final de la obra. Respecto al dominio visigótico sobre Vasconia, habría sido claro desde el reinado de Suintila, fundador de Olite, hasta el de Recesvinto en el que se habrían producido algunos levantamientos. Wamba les habría sujetado definitivamente, no registrándose ninguna rebelión vascona hasta la irrupción de los árabes. Risco contradice así a Moret para quien los vascones con posterioridad a la expedición de Wamba, no habrían quedado "enteramente rendidos". ${ }^{55}$ Para Risco, inmediatamente antes de 711 Vasconia habría estado gobernada por los Duques de Cantabria, "elegidos del linage de los Reyes Godos".

Risco rechaza la opinión de "muchos de los Escritores modernos que han tratado largamente del origen del Reyno de Navarra, empeñándose en defender, que la dignidad Real se estableció en la Vasconia luego que se perdió España, y que los Navarros nunca estuvieron sujetos a los Reyes de Asturias". ${ }^{56}$ Juzgando de quiméricas y fabulosas las tesis de Moret acerca de los primeros reyes navarros, Risco sostiene que en los años próximos a la pérdida de España hasta que los Moros conquistaron Pamplona, los Vascones obedecieron primero a los Duques de Cantabria y después a los Reyes de Asturias. ${ }^{57}$

Llegados a este punto, Risco introduce una distinción semántica entre navarros y vascones. Mientras los primeros serían los habitantes de Pamplona y de la mitad sur de Navarra, dominados por los árabes, los segundos serían los habitantes de la Montaña que habrían permanecido independientes. ${ }^{58}$ Éstos últimos habrían sido los vencedores en Roncesvalles frente a Carlomagno en 778 gracias a la ayuda prestada por los gascones de la Novempopulania. ${ }^{59}$ Asimismo, en su afán por negar la existencia de una entidad política independiente dotada de capacidad militar, Risco retrasa la batalla de Olast, en la que los roncaleses derrotaron a Abderramen, del año 785 al año 961, en tiempos ya de Abderramen III y de Garcia Sancho de Navarra. ${ }^{60}$

${ }^{54}$ Risco, M. 1779a: 3-4.

55 Ibidem: 337-338.

56 Ibidem: 344.

57 Ibidem: 348. En la página 375 afirma Risco en relación con Moret, su "firme creencia" de que el cronista navarro no sólo no contaba "exactamente los sucesos que conciernen a la Vasconia, sino que por atribuir a los Navarros, Reyes, y empresas fabulosas, en lugar de honrar a su Nación, la envilecen imputándola hechos que realmente la servirían de afrenta si fueran verdaderos".

\footnotetext{
58 Ibidem: 352-356.

59 Ibidem: 362.

60 Ibidem: 365-371.
} 
En su reconstrucción, Risco afirma que desde 711 a 778 estuvo Vasconia sujeta a los Reyes de Asturias y que desde 778 a 824, Pamplona habría estado en manos de los francos, el sur de Navarra en las de los árabes y la zona norte en la de los vascones. Desde 824 hasta el reinado de Alfonso II de Asturias, Vasconia habría estado dominada por los reyes asturianos. El reino de Navarra habría nacido muy entrado el siglo IX con Iñigo Arista que, con todo, no habría llegado a gobernar a los navarros "con pacífica posesión como Rey, o Soberano independiente de los Reyes de Asturias". Entre 850 y 870 los navarros habrían intentado en vano en varias ocasiones liberarse del dominio leonés. A pesar de que Garcia Iñiguez habría sido el primer rey "que obtubo la dignidad de Rey absoluto de los Navarros", para Risco, "los Reyes de Navarra vienen de la sangre real de los Godos de España" a causa del largo periodo de dominación de los reyes asturianos sobre Navarra y por los lazos de parentesco que unían a García Iñiguez con los reyes de Asturias y León a través del Duque de Cantabria. ${ }^{61}$

\section{LA PRIMERÍSIMA REACCIÓN A LAS TESIS DE RISCO: LA PROPUESTA DE JUAN ANTONIO FERNÁNDEZ A LAS CORTES DE NAVARRA.}

Todas esas tesis de Risco suscitaron una primerísima reacción del que fue el mejor historiador navarro de la segunda mitad del siglo XVIII: el tudelano Juan Antonio Fernández. Nacido en Tudela en 1752 y fallecido en la misma ciudad en 1814 ordenó desde muy joven numerosos archivos en Tudela, Uclés, Madrid y Zaragoza, algunos de ellos muy importantes como el de la Orden de Santiago o el de la Orden de San Juan de Jerusalén. En 1793 Carlos III le designó Archivero General de la Orden de Santiago y en 1802 Carlos IV Oficial primero del Archivo de la Primera Secretaría de Estado, cargo que no llegó a ocupar. Llegó a ser nombrado Académico correspondiente de la Real Academia de la Historia en razón de sus aportaciones a la Sección Primera del Diccionario Geográfico-Histórico de España confeccionado por esa institución y relativo a Navarra, Vizcaya, Álava y Guipúzcoa, tal y como se recoge en el prólogo de esa obra, entre los agradecimientos. Respecto a la valoración de su obra y a su erudición, baste recordar que, además de lo referido en los párrafos anteriores, en un tomo de España Sagrada Vicente de la Fuente consignó "que era un librero de Tudela y hombre que, a fuerza de estudio y talento llegó a ser uno de los anticuarios españoles más notables a fin del siglo XVIII". Asimismo, Castro Álava enjuició que "Juan Antonio Fernández es de todos los hijos de Navarra el cultivador más excelso de las ciencias históricas", coincidiendo su vida con la de autores como Flórez, Risco, Masdeu,

61 Ibidem: 391-410. 
Mayans y Císcar en los que "los estudios históricos revelan erudición y crítica". Con todo, es preciso advertir que nos encontramos ante un historiador cuya obra, en su casi práctica totalidad, permaneció inédita en formato de manuscrito y que, además, en su mayor parte desapareció con el desmembramiento y venta por partes de su biblioteca. ${ }^{62}$

En un memorial que envió a las Cortes navarras el 20 de marzo de $1781^{63}$ Juan Antonio Fernández exponía que había encontrado en la obra de Risco "negadas muchas de las glorias de este llustrísimo Reyno; pero entre todas, ninguna más digna de vindicta, que la de suponer el establecimiento de sus primeros Reyes, posterior a el año de 883". Juan Antonio Fernández valoraba más que la consistencia de la obra de Risco, su penetración en el mercado y el status obtenido por el autor con el beneplácito de la Corte. En relación con ello, afirmaba lo siguiente: "La obra de la Vasconia, va introduciéndose cada día más; y podría temerse que el crédito y autoridad que se ha adquirido el que la escribió bastase a despojar a V. S. Y. de la antigüedad de su corona. Ya ha tres años que se dio a luz, sin que en este intermedio se haya impugnado; lo que puede proceder de necesitarse algún tiempo para tratar con solidez un asunto que merece el mayor cuidado, y diligencia". Fernández se refería al deber cívico del historiador para con su comunidad: "El desempeño de la obligación con que nacemos de defender la Patria, y la de aplicar al común beneficio nuestros talentos, ha hecho al Exponente aprontar memorias y documentos que por sí solos, y sin necesidad de inducciones demonstrarán que ya tenía V. S. Y. Reyes particulares cerca de un siglo antes de lo que supone el P. Risco". El historiador tudelano prometía cumplimentar esa labor, garantizando "que no es nuevo vencer los

62 Sobre su biografía pueden consultarse las siguientes obras: Sáinz y Pérez de Laborda, M. 1913. Apuntes Tudelanos: 388-401. Tudela; Castro Álava, J. R. 1941. "Figuras tudelanas: Juan Antonio Fernández, Archivero de la Orden de Santiago". Revista Príncipe de Viana 2: 95-122; Castro Álava, J. R. 1963. Autores e impresores tudelanos: 365-389. Pamplona, Institución Príncipe de Viana; Castro Álava, J. R. 1974. Juan Antonio Fernández: un tudelano del siglo de la llustración. Pamplona, Diputación Foral de Navarra-Dirección de Turismo, Bibliotecas y Cultura Popular; Fuentes Pascual, F. 1955. "Más sobre Juan Antonio Fernández". Revista Príncipe de Viana 59: 203-234; Canellas López, A. 1979. "Los estudios paleográficos en España y el archivero Don Juan Antonio Fernández", en Palaeographica, Diplomatica et Archivistica. Studi in Onore di Giulio Battelli: v. II, 616- 633. Roma, Edizioni di Storia e Letteratura. Por otra parte, acerca de sus manuscritos y de su importante biblioteca hemos publicado recientemente dos artículos. Cfr. Mikelarena Peña, F. 2006. "Los manuscritos de la biblioteca de Juan Antonio Fernández, erudito tudelano". Príncipe de Viana 237: 273-299; Mikelarena Peña, F. 2008. "Los libros de historia de la biblioteca de Juan Antonio Fernández, erudito tudelano y académico correspondiente de la RAH". Príncipe de Viana 244: 459-495.

${ }^{63}$ AGN, Reino, Sección de Historia, Literatura, Legajo 3, Carpeta 6 
pequeños, a los más elevados gigantes".

Las Cortes decidieron el mismo día en que se presentó el memorial que la Diputación se encargara del examen de la obra de Fernández cuando éste la presentase ultimada. ${ }^{64}$ Sin embargo, Fernández no aportará, por lo que sabemos, manuscrito alguno, quizás porque las instituciones navarras no le ofrecieron cantidad remuneratoria alguna por anticipado, algo que dada la cualificación y solvencia del erudito tudelano, a pesar de su relativa juventud en 1781, podía ser esperable por parte de éste. Sólo en 1804, al socaire de la polémica con Traggia, del que más adelante hablaremos, algún miembro de la Diputación se acordó de la oferta de Fernández y en la sesión de 5 de diciembre de aquel año la institución rectora de Navarra acordó "que se escriba a Fernandez el de Tudela si ha de embiar la obra que prometió por las Cortes de ochenta y ochenta y uno, contra el Padre Risco". ${ }^{65} \mathrm{De}$ cualquier forma, a pesar de ese tardío requerimiento, la realidad es que la Diputación navarra nunca hasta entonces había pensado en contar con los servicios de Juan Antonio Fernández, el principal exponente de la historiografía navarra de la época. Dado que Fernández se vio obligado a buscarse el sustento fuera de Navarra, podemos pensar que el recordatorio de su persona en 1804 no suscitaría en él demasiado entusiasmo, en especial porque tampoco ahora había detrás una oferta clara.

La respuesta de las Cortes a Fernández, persona que poseía los suficientes avales como historiador y como erudito de cara a que su oferta fuera tenida en cuenta, supuso la pérdida de la oportunidad de elaborar un discurso historiográfico de respuesta a los aires de refutación de las tesis de Moret que venían de Madrid. Seguidamente veremos cómo tampoco la Diputación daría el visto bueno, por no apreciar garantías en él, al ofrecimiento que les planteó el roncalés Miguel de Hualde, un outsider en el plano historiográfico, con más voluntad que acierto, que, además, complementaba la exaltación del origen diferenciado de los reyes navarros con un vasquismo rotundo y larramendiano del que no existe ningún otro ejemplo en la época en Navarra.

\section{EL AFÁN CORRECTOR DE MIGUEL DE HUALDE Y LA EVALUACIÓN CRÍTICA DE FRANCISCO DE ARBELOA.}

Hablar de Miguel de Hualde en el plano historiográfico puede parecer peregrino porque las obras que se van a mencionar no pasaron del estado de manuscrito y porque, a pesar de su afán por presentarse

\footnotetext{
${ }^{64}$ AGN, Actas de Cortes, Libro XII, f. 1092v.

${ }^{65}$ AGN, Actas de Diputación, Tomo 28, f. $18 \mathrm{v}$.
} 
como historiador, no lo era en absoluto. Además, los textos que vamos a recoger son más bien críticas y compendios de noticias historiográficas de otros autores, algunos historiadores propiamente dichos, pero otros no. De cualquier forma, su figura resulta llamativa porque, tras haber dedicado la mayor parte de su vida a otros quehaceres, de forma monotemática y compulsiva, a partir de los años ochenta registró una conversión de sus actividades literarias, volcándose hacia el pasado de Navarra de una manera apologética. En su intento se siente el anhelo del historiador aficionado que quiere ejercer como agitador, incorporando algunas consideraciones que provienen de ámbitos extrahistoriográficos, todo ello bajo una cierta convicción de que todas las cuestiones a las que alude estaban siendo cuestionadas, requiriéndose de una respuesta en el plano discursivo. El motivo que espoleará su activismo historiográfico será la publicación en 1779 del tomo de la España Sagrada referido a Vasconia, escrito por Manuel Risco.

Disponemos de algunos datos sobre Miguel de Hualde. Pérez Goyena $^{66}$ dijo de él: "Natural de Isaba en Roncal (...). Tomó el hábito de carmelita calzado u observante, y aunque los Superiores insistieron en que estudiase la carrera eclesiástica él quiso permanecer de lego. Destinósele al convento de Sevilla, donde escribió un libro que lleva por título Notas al destierro merecido de opiniones equivocadas. Sevilla. Su objeto es manifestar los errores del Calendario hecho en 1582 por Gregorio XIII, proponiendo la rectificación y adopción de uno que él ideó. Escribió un memorial al Rey pidiéndole ayuda para la divulgación del libro y envío de ejemplares a las Academias extranjeras. Se rechazó la obra por Real Orden de 27 de diciembre de 1765. El trinitario Fr. Pedro de San Martín Uribe, catedrático de Astronomía en la Universidad de Sevilla, combatió la obra, como también D. Diego Torres y D. Isidoro Ostiz, profesores de la Universidad Salmantina, pero Hualde continuó defendiendo con gran ardor su teoría. Se titulaba El Contador Lego. Fue también historiador como lo muestran estas dos obras manuscritas: Apología reformada del P. José Moret vindicándole de la impugnación de algunos historiadores, y de las del P. Risco, compuesto por Fr. Miguel de Hualde... $2^{\circ}$ Compendio apologético historia de Navarra por él mismo. Pidió Hualde a la Diputación ayuda de costes para la impresión de un Compendio histórico acerca de los primeros reyes de Navarra. La Diputación le niega el socorro demandado y por los buenos deseos le regaló una onza de oro. Se cree que falleció en 1780". Como veremos, la fecha de su fallecimiento es incorrecta, puesto que esos últimos manuscritos a los que aludía Pérez Goyena son posteriores a la fecha que consignó.

66 Pérez Goyena, A. 1951. Ensayo de bibliografía navarra: desde la creación de la imprenta en Pamplona hasta el año 1910: IV, 380. Pamplona: Diputación Foral de Navarra. 
Según Pérez Goyena, ${ }^{67}$ sus obras serían las dos siguientes: Asunto, serio, grave, e importante, que se propone a resulta de lo que se ha trabajado hasta ahora, sobre la más justa computación del tiempo, Pamplona, 1775 (obra vuelta a imprimir en 1778) y Arithmetica demonstrada con diversas prácticas cuentas de las quatro reglas para que la juventud pueda instruirse con brevedad, Pamplona, 1776.

No obstante, en el Catálogo Colectivo del Patrimonio Bibliográfico accesible a través de Internet pueden encontrarse, además, las siguientes: El contador lego, especulativo y práctico sobre varios assumptos de arithmética civil y astronómico (Madrid, 1758); Destierro merecido de opiniones equivocadas, y justamente deseada nueva corrección de tiempos (Madrid, 1758 y 1765); Astronómicas reflexiones (Madrid, 1758); Claro resumen del nuevo systema astronómico (Madrid, 1768); Combate astronómico (Madrid, 1767); Triunfo de la verdad sobre los inciertos sistemas que la obscurecen (Pamplona, 1787); Demostración de la cuenta que el tiempo ha efectuado (Pamplona, 1786); Compendio de la era christiana y los años julianos (Madrid, 1758); Demonstración a punto fijo de los soberanos mysterios de la encarnación, pasión de Jesuchristo (Madrid, 1765). También fue autor de otras obras en las que polemizó con otros autores.

Por otra parte, en el Archivo Histórico Nacional figuran varios manuscritos suyos sobre materia astronómica, así como un Catálogo de los reyes de Navarra. ${ }^{68}$ Ese manuscrito sería posterior a los que vamos a comentar posteriormente y en él se afirma la primacía del reino de Navarra sobre el reino asturiano fundado por Don Pelayo. Se dice en él que tras la batalla de Guadalete "se apoderaron los moros de todas las tierras llanas, quedando solamente reserbadas, las montañas de Asturias, Santander, Vizcaya, Navarra y Aragón, etc., según va dicho en la compendial historia, espresando en ella, las causas, y motibos que precedieron, para que se erigiesen a un mismo tiempo las Dos Dignidades Reales, la de Asturias y la de Navarra haviendo sido el primer Rey de este Reyno de Navarra". Por otra parte, aunque no comenta la conquista de Navarra por parte de Castilla de 1512 de ninguna manera políticamente incorrecta, ${ }^{69}$ Hualde considera a la par a los reyes

${ }^{67}$ Ibidem: $380-381$ y 390-391.

${ }^{68}$ Se encuentra en Archivo Histórico Nacional, Códices, L. 297.

${ }^{69}$ Afirma que en el contexto de la guerra de la Liga Santa se le declaró al rey de Navarra "enemigo de la Yglesia Cathólica, solo porque no quiso hazerle Guerra al de Francia (el qual hera tío suyo) y al que por esto, le quisiese privar del Reyno, dando facultad, por su Bulla, al Rey Cathólico Don Fernando, para que se apoderase de este Reyno de Navarra. Por dichos motibos, o porque quiso retener en su memoria el dicho Don Fernando el Cathólico, haver reynado su Padre Don Juan $2^{\circ}$ en este Reyno de Navarra, como marido de Doña Blanca $2^{a}$ (Reyna propietaria) y de que el Príncipe Don Carlos su 
descendientes de Fernando el Católico, situándolos bajo una relación encabezada por el título de Drecho del Rey Cathólico Don Fernando, con los reyes descendientes de los reyes despojados, situados bajo una lista encabezada por el enunciado Drecho de Doña Cathalina y don Juan de Labrit. También menciona que ambas líneas permanecieron sin ceder "el Drecho a esta Corona de Navarra, hasta que después de 188 años, providenció el Altísimo, el que se enlazasen los dos Drechos, en una persona", que sería Felipe $V$ de Castilla. Así pues, Hualde interpreta la restauración de la plena legitimidad con la confluencia de ambas líneas con la llegada de los Borbones con Felipe V. De hecho, afirma que "Damos asimismo la noticia delineada de los Dos Reales Drechos, por donde a Nuestro Reynante Monarca el Señor Don Carlos $3^{\circ}$ de Castilla y $6^{\circ}$ de Navarra, le corresponde la Posesión de esta Corona, por lo deribado de la Magestad del Señor Don Fernando el Cathólico; y a la de la Señora Doña Cathalina y Don Juan de Labrit; Drechos que unió y enlazó el Altísimo después de 188 años, según y como va dicho y delineado". Esas tesis son las mismas que defendió Alesón, el historiador que continuaría el trabajo de Moret en los Anales del Reino de Navarra. ${ }^{70}$

Con todo, son más importantes los otros dos manuscritos de respuesta de Hualde a Risco: el titulado Compendial Apologética Historia y el que lleva como cabecera Estímulos apologéticos, y puntos de meditación historial.

La Compendial Apologética Historia de Hualde y la crítica del benedictino Arbeloa.

Primogénito hijo, murió antes que su Padre, el dicho Don Juan $2^{\circ}$ y que por este reino le pudo corresponder drecho de heredar a su hijo; sin manifestar estos designios al Público". Además, indica que los Diputados del Reino en una entrevista le preguntaron al Duque de Alba, jefe de las tropas castellanas, "porqué se hacía tan repentina imbasión, respondiéndoles que en virtud de la Bulla del Papa Julio $2^{\circ}$ que dava orden para ello por ser Don Juan de Labrit, su Rey Herege Cismático, a lo que replicaron los Diputados, que dado el caso que lo fuese, que no lo era el Reyno, sino muy fiel hijo de la Yglesia cathólica y defensor de ella, que tenía Drecho y facultad el Reyno, para privarle de la corona, al que no fuese defensor de ella; y en suma añadieron, que así como podía nombrar el Reyno a otro, le nombraron al Rey Cathólico con tal que Su Magestad admitiese la corona, como Reyno separado del de Castilla y Aragón; y jurase la observancia de sus Fueros y Leyes; el Duque de Alba, dio parte al Rey Cathólico, combino su magestad y en su virtud dándole sus Poderes al dicho Duque de Alba, se efectuó el Contrato, y tomó la Posesión el Rey Cathólico, acudiendo a prestarle el juramento de vasallaje, los Apoderados de las ciudades, valles, villas, y la Nobleza".

${ }^{70}$ Cfr. Floristán Imízcoz, A. 2000. "Examen de la conquista castellana. La introspección de los cronistas navarros (siglos XVI-XVIII)". Príncipe de Viana 219: 121-123. 


\section{LA VASCONIA DE MANUEL RISCO Y LA POLÉMICA SUBSIGUIENTE 321 SOBRE EL PASADO DE NAVARRA}

En noviembre de 1783 Hualde exponía a la Diputación que había advertido en el contenido del tomo 32 de la obra intitulada La España Sagrada, publicada en 1779, "una impugnación contra la Historia general de este Reyno, escrita por su cronista, el Muy Reverendo Padre Moret (que goze de Dios) dirigida a presuponer que no hubo en este Reyno los quatro o cinco Reyes que precedieron a Don Yñigo Arista $2^{\circ}$ en suma". Asimismo, había notado que en aquella obra se erraba en la datación de la Batalla de Olast, ganada por los roncaleses a los musulmanes, "retrasándola al 961, haviendo sucedido el 786". Estando Hualde "también noticioso de la impugnación que hazen a las obras de Moret otros clásicos autores" en relación con "el establecimiento de la Dignidad Real", había "trabajado la compendial Apologética Historia" que presentaba ahora a la Diputación, solicitando permiso para su impresión y "alguna ayuda de costa, para sus urgencias religiosas, en consideración de ser el contenido de la obra, para mayor aumento, del Glorioso Timbre y Blasón de V.S. Yllma.". Hualde notificaba que se hallaba "en el año 78 de su edad". ${ }^{71}$

La Diputación encargaba en mayo de 1784 la evaluación de la calidad del manuscrito a Fray Francisco Arbeloa, monje de Leire, a quien contemplaba "dotado de todas las prendas correspondientes para hacer una juiciosa crítica" de la obra remitida por Hualde. En el encargo, la Diputación transmitía que, en relación con la polémica sobre "la antigüedad de la erección de la Dignidad Real en Navarra, pretendiendo representar fabulosos los Reies anteriores a don Iñigo Arista, cuio reinado pertenece al siglo nueve", lo que había sido "el Pomo de la Discordia de los Historiadores", desde su punto de vista "nuestro exatísimo Analista Moret" se había esforzado "en acreditar la verdad de el establecimiento del Real Trono en este Reino quasi al mismo tiempo que en las Asturias". La Diputación añadía: "Asi el Padre Risco no hace sino repetir lo que otros Históricos Castellanos; y como Moret fundó con todo el nerbio y erudición que permite la obscuridad de las cosas en una antigüedad remotísima; dudo que el Padre Hualde adelante en el asunto, y también si los motivos con que se empeña en ilustrarle, se afianzaran en firmes vasas, y si el estilo y método de la disertación, que intenta dar a la Prensa este Religioso, son tales que por ello no desmerezca ver la

71 AGN, Reino, Sección de historia, literatura..., Legajo 3, carpeta 7: Censura del Padre maestro don Fray Francisco Arbeloa al libro que escribió el carmelita lego Fray Miguel Hualde, acerca de la compendial apologética historia de Navarra. Siguen unos memoriales de este y oficios de la Diputación (1784). Hay que decir que existe también otro manuscrito de Hualde de refutación a Risco en la Biblioteca de la Real Colegiata de Roncesvalles, titulado Reflexiones históricas contra el Tomo 32 de la España Sagrada del P. Fr. Manuel Risco, que no comentamos porque se centra sobre todo en la batalla de Olast y en salvaguardar los honores y privilegios del valle de Roncal, de donde era nativo el autor. 
pública luz este escrito".

La crítica de Arbeloa estaba fechada el 2 de julio de 1784. Arbeloa declaraba que para realizar ese trabajo había leído con atención tanto las obras de Moret como el tomo 32 de la España Sagrada, obra de Manuel Risco, continuador del Padre Flórez, así como "algunos instrumentos" del archivo de Leire y el propio manuscrito de Hualde.

En opinión de Arbeloa, "Tres parece que son los sugetos agraviados por el Padre M. Risco. El primero y principal el Yllmo. Reyno de Navarra; el segundo el Valle de Roncal; y el tercero el Padre Joseph Moret. Al primero lo despoja de su principal ornamento. Al segundo lo trastorna su privilegio predilecto, $y$ al tercero lo trata ignominiosamente. $Y$ aunque me desvíe algún tanto del orden y méthodo de la censura, empezaré por éste último a justificar mis aserciones. Repito, pues, que al Padre Joseph Moret vulnera notablemente el Padre Manuel Risco; porque lo trata de hombre de más subtileza, que sinceridad; de hombre que en lo que escrivió tocante a los primeros tiempos de la restauración de España, fue gobernado más del afecto acia su Patria, que de las luces, que tenía en los antiguos; Y últimamente que aunque adornado de las nobles calidades de ingenio y agudeza, se aprovechó de estas prendas para lisonjear el gusto de los que miran sus propias glorias más con pasión ciega, que con ingenuidad discreta". ${ }^{72}$

Arbeloa, en su crítica de la obra de Hualde, defiende tanto el estilo literario como las intenciones perseguidas por Moret. En relación con éstas últimas, Arbeloa pregunta: "Quién le ha dicho al Padre Risco, que el Padre Moret era más subtil que sincero? Quién le ha asegurado, que escrivía lo que escrivió; por lisongear el gusto de los Navarros, y sus apasionados? Todo esto, y algo más, que dice en su obra, equivale a decir, que el Padre Moret era un hombre, que escrivió lo contrario de lo que entendía, y que era un vil adulador de los apasionados a Navarra. Verdaderamente, que de ninguna de estas claúsulas necesitaba el Padre Risco para ilustrar el tratado de la Vasconia". ${ }^{73}$

Arbeloa hace referencia, asimismo, al principal defecto de la obra de Risco. Según él, "algo más pesada lleva la mano el Padre Manuel Risco con el Yllmo. Reyno de Navarra, a quien, como ba insinuado, despoja de su principal hornato, que son los cinco primeros Reyes anteriores a Don Yñigo Ximénez, comúnmente llamado Arista, y negándole estos Reyes, lo priva de la gloria de haver empezado la restauración de la Monarquía al mismo tiempo que el Reyno de Asturias. Y lo más gracioso es que los que le concede después hasta Don García Yñiguez segundo los extenúa, y desnuda tanto de las prerrogativas

72 Subrayado en el original.

73 Subrayado en el original. 
Regias que más parecen Caciques de la América, que antiguos Reyes de Navarra; pues ni les da la pacífica posesión del Reyno, ni los hace Reyes absolutos, sino dependientes de los de Asturias". Arbeloa replica a Risco que Moret, precisamente ante las críticas de Oihenart, ya había acreditado suficientemente la existencia de esos reyes primeros, añadiendo "que el Padre Risco se hace sospechoso de no haver procedido de mui buena fee en esta disputa histórica; porque omitió (a caso con algún cuidado) aquellos fundamentos más sólidos, que el Padre Moret produxo, para cimentar su opinión, y sólo sacó al campo de la disputa las razones más débiles y que pueden llamarse de congruencia". ${ }^{74}$

Seguidamente, Arbeloa describe las fuentes documentales y los argumentos utilizados por Moret, mencionando que ignora "el motivo, que tuvo el Padre Risco, para omitirlos y pasarlos en silencio, tomando a su cargo tan solamente deshacer una prueba, que en realidad es la más débil, de quantas aduce el dicho Analista. Verdaderamente, que cualquiera que repare con crítica inspección sobre el conjunto de todas estas cosas, se persuadirá sin repugnancia, que el Padre Manuel Risco no ha escrito su tratado de la Vasconia con tanta imparcialidad, como pondera, sino con notoria desafección a las glorias de Navarra". Seguidamente pasa a criticar los fundamentos de las tesis sostenidas por Risco y, sobre todo, su proposición de "que los mencionados Reyes eran dependientes de los Reyes de Asturias, cuia soberanía reconocieron los de Navarra hasta tiempos de Don Alonso el Magno". En opinión de Arbeloa, "Pero de dónde saca esta anécdota tan peregrina?. Qué author coetáneo se la ha dicho? Qué instrumento, qué Archivo se la ha manifestado?. Es posible, que si los Reyes de Asturias hubieran dominado en Navarra como soberanos en estos tiempos, no havía de constar de algún Archivo? No lo havía de decir alguna donación? Que Don Yñigo Ximénez Arista era Rey de los Navarros, consta por instrumentos authénticos de este Monasterio; pero que reinase baxo el Ymperio de los Reyes de Asturias, ni lo dice instrumento alguno auténtico ni lo persuade algún author coetáneo. Que Don Alonso subyugó a los Vascones, como dice el Obispo Vampiro, no prueva, que este Monarca fuera Rey de los Pamploneses o Navarros; porque ya le tiene dicho el Padre Moret al Padre Risco, y de todo el Mundo, que con el nombre de Vascones se entendían también los Alaveses, y éstos fueron los únicos que Don Alonso sujetó a su Ymperio. Finalmente: no puede ni debe prevalecer una conjetura, que no sin violencia se deduce de un author contra unos instrumentos tan solemnes, como la donación de Don Yñigo Ximénez en el año de 842, y la de su hijo Don García Yñiguez en el de 880". En apoyo de su crítica, Arbeloa menciona al cronista aragonés Jerónimo Zurita "que aunque en sus Anales miró con desprecio; y reputó

\footnotetext{
${ }^{74}$ Subrayado en el original.
} 
por ficticios los Reyes anteriores a Don Yñigo Ximénez, reformó en los índices esta su opinión" basándose en la documentación que consultó en el intervalo y siguiendo la regla establecida por el historiador Ambrosio de Morales "que las historias se han de corregir por los instrumentos, no los instrumentos por las historias".

Después de establecido todo lo anterior, Arbeloa pasa a ocuparse de la crítica del manuscrito de Hualde. A juicio de Arbeloa, a pesar de "las bien fundadas quexas, que tienen los Navarros de la inmoderada crítica del Padre Manuel Risco" y de "los conatos y esfuerzos, con que Fray Miguel Hugalde ha procurado propugnar las antigüedades de este Yllmo. Reyno", Hualde falla "en la producción de pruebas, y en la solución de los argumentos, que contra ellos produce el Padre Manuel Risco". Es una lástima "que siendo tan buena la causa por un común ni prueba lo que ofrece, ni disuelve lo que se objeta". Además, "en muchas partes disiente de lo que dice, y prueba el Analista de Navarra; en otras asienta proposiciones mui interesantes sin apoyo de escritor coetáneo y autorizado, y sin documento de algún Archivo respetable; $Y$, ya se vee, que siendo unos y otros lo que en tiempos tan remotos inducen a un prudente asenso, faltando estos fundamentos, se queda el letor con tanta desconfianza, y ambigüedad, como la que tenía antes de leer y rexaminar el asumpto". Seguidamente pasa a aportar pruebas de su negativa evaluación de la obra de Hualde, recogiendo diferentes partes de su manuscrito, entre los cuales las menos afortunadas serían justamente los de mayor importancia

Así por ejemplo, en relación con la tesis de Risco de que "en su opinión empezó el Reyno de Navarra con absoluta independencia algunos años después del casamiento de Don Alonso el Magno con Doña Ximena hija del Rey de Navarra Don García Yñiguez, quien, según el dicho Risco, fue el primero entre los Reyes de Navarra, que empuñó el cetro con esta independencia", Arbeloa recuerda que en lugar de impugnar Hualde esa "peregrina aserción con documentos fuertes de instrumentos, donaciones, y chronicones de aquellos tiempos, que se encuentran abundantes en los Archivos, se acontenta con la frescura de decirle (y sin razón) que la Muger de Don Alonso el Magno era Francesa, y no Navarra, que primero se llamó Madama Amelina, y después Doña Ximena; y por último, que Don García no tubo hija alguna con el nombre de Ximena". "Todo esto, aunque fuera cierto, que no lo es, qué prueba? Convence acaso, que la dignidad Real absoluta, e independiente, que es el objeto principal de la disputa, empezó antes de los tiempos de Don Alonso el Magno? Que antes de Don García Yñiguez havía en estas regiones Reyes de Navarra con absoluto imperio?. De ningún modo. Lo más que se puede concluir de lo que asienta Fray Miguel, es que a Don Alonso le atribuien una Muger, que no ha tenido, y a Don García una hija, que no ha enjendrado. Pero téngase entendido, que así el Padre Risco, 


\section{LA VASCONIA DE MANUEL RISCO Y LA POLÉMICA SUBSIGUIENTE 325 SOBRE EL PASADO DE NAVARRA}

como el Padre Moret, y otros historiadores están acordes en que la Muger de Don Alonso fue Doña Ximena hija de Don García Yñiguez Rey de Navarra, y que con este enlace se radicaron más y más la paz y la amistad de ambos Monarcas".

Arbeloa termina indicando que su censura de la obra de Hualde "crecería inmensamente" si recogiera "todas las equivocaciones ierros, y voluntariedades" presentes en el manucrito de aquél, así como si se hiciera cargo del estilo que lo considera muy inferior al estilo de Moret o de Risco.

Desde luego, dada la importancia del ataque de Risco al basamento historiográfico de la foralidad navarra y dada la evaluación negativa que hizo Arbeloa del intento refutador de Hualde, llama la atención que a nadie en la Diputación se le ocurriera encargar al benedictino la tarea de replicar a Risco, sobre todo, cuando en los párrafos anteriores se puede apreciar con claridad que conocía a fondo las debilidades de la obra del agustino riojano y que disponía de los argumentos suficientes para desmontar sus tesis.

Otros intentos apologéticos de Miguel de Hualde en relación con la Historia de Navarra

Con todo, Hualde no se dio por desanimado. En diciembre de 1790 escribió Hualde a la Diputación una carta en la que planteaba que, habiendo presentado a la misma una obra titulada Compendial Apologética Historia relativa a los primeros catorce reyes navarros y hecha "a imitación de la Historia intitulada Sucesión Real de la Corona de León y Asturias", para que la analizase y para que decidiese sobre el permiso para su eventual publicación, concediendo de paso alguna ayuda económica de cara a afrontar los costes. La obra pretendía responder a La Vasconia de Risco en la que, según Hualde, éste "se sirvió (...) estampar impugnación contra la Historia General de este Reyno, negándole a su Coronista, el Padre Josef Moret (que goze de Dios) los quatro primeros Reyes que ubo, franqueándole al Yllmo. Reyno (a su Capítulo 19) algunas expresiones; menos respetuosas de las que les corresponden". Hualde había escrito la respuesta, en defensa del honor de Navarra y también de su valle natal, "en virtud del Amor que sostiene a su Patria, todo Patricio". La Diputación no apoyó la petición, si bien acordó pagar a Hualde una onza de oro por sus esfuerzos. ${ }^{75}$

75 AGN, Reino, Sección de Historia, literatura..., legajo 3, carpeta 9: Memoriales de Fray Miguel Hualde religioso carmelita pidiendo a la Diputación del Reino una ayuda de costa para la impresión de un compendio histórico que había compuesto acerca de los primeros reyes de Navarra. la diputación no tuvo por conveniente la impresión, y por los buenos deseos del autor le regaló 
Tampoco ello fue suficiente para calmar el afán corrector de Hualde de las críticas hechas a las glorias de Navarra por algunos autores. En 1792 presentaba a la Diputación un papel anónimo titulado Estímulos apologéticos, y puntos de meditación historial en donde criticaba los comentarios negativos efectuados sobre Navarra y su historia, en muchos casos con carácter absolutamente puntual, por una amplia nómina de autores. ${ }^{76}$ Entre ellos están Capmany, Méndez, Lamberto de Zaragoza y Joaquín Traggia.

Con todo, es de remarcar que para defender su tesis de "que los Navarros nunca fueron dominados por nación alguna del mundo, y los actuales son legítimos descendientes por serie no interrumpida de los primeros pobladores", recurra sin citarlo a Sanadon, en sus palabras, "Autor del Ensayo sobre la Nobleza de los Bascongados para que sirva de Introducción a la Historia general de aquellos pueblos, que se dio a luz en francés en 1785 en Pau, y vertida en Español, con timidez prudente en algunos pasages, en Tolosa de Guipúzcoa en el de 1786 por cuyos fundamentos, que ya se sabe son de los más legales, prelativos y aun radicales ambos concordes y concurrentes, prefiere la nobleza de nuestro Reyno y Vascones a la de todas las naciones de Europa". ${ }^{77}$

También Hualde se hace eco de las tesis de Larramendi, exponiéndolas, además, con una radicalidad similar a como las presentaba el jesuita andoaindarra: "El haverse conservado la lengua vascongada, lengua, en cuyo elogio se pudieran añadir otros muchos sobre los que deduxo Larramendi, es otro argumento al qual todavía los más presumidos émulos no pudieron hallar salida. $Y$ quando para conservarla no huviera otro motivo; sólo para prueva de la limpieza, separación, inmunidad sin conmistión de otra nación alguna, a toda costa conviene conservarla. ¿Es posible? Y como lo es, y prueva invencible; merece darle más vigor sobre el robusto que se le descubre". Y a esa consideración añade un párrafo que sorprende: "Para hacerlo conviene suponer lo que la esperiencia, la política, y aun la inclinación natural persuaden a todo el mundo; y es que quando una Nación se señorea de otra, se aplica con mucho desvelo a introducir en la sojuzgada sus usos, y costumbres, sus modas y forma del vestido, sus leyes por supuesto \&, pero sobre todo a sofocar el idioma y lenguage de los supeditados, e introducir y arraygar el suyo propio de los dominantes". A través de su defensa militante de la lengua vasca, en cuanto que nativo de un valle tal

una onza de oro (1790).

${ }^{76}$ AGN, Reino, Sección de Historia, literatura..., legajo 3, carpeta 12: Papel anónimo titulado Estímulos apologéticos y puntos de meditación historial; quéjase de algunos impresos que tratan de oscurecer la antigüedad y las glorias de Navarra (1792).

77 Subrayado en el original. 


\section{LA VASCONIA DE MANUEL RISCO Y LA POLÉMICA SUBSIGUIENTE 327 SOBRE EL PASADO DE NAVARRA}

euskaldún por aquel entonces como el de Roncal, podría ejemplificar la hipótesis de Larrañaga Elorza de que el vascocantabrismo en Navarra se habría implantado, sobre todo, en la Navarra vascoparlante, siendo marginal en la Navarra más meridional en la que no hay constancia de presencia de aquella lengua durante la Baja Edad Media ni durante la Edad Moderna. ${ }^{78}$

${ }^{78}$ Larrañaga Elorza, K. 1998: 476-477. No obstante, también hay que señalar que el ejemplo que cita de Francisco de Elorza y Rada, autor de la obra publicada en 1714 Nobiliario de el valle de la Valdorba, y en el que "no hay ni rastro de Túbal ni, desde luego, de los vascocántabros" (Ibid., p. 477) no es correcto puesto que la Valdorba fue un enclave vascoparlante hasta mediados del siglo XIX, tal y como muestra el mapa dialectal del Príncipe Bonaparte (Cfr. Bonaparte, L. L. 1863. Carte des septs provinces basques mostrant la délimitation actuelle de l'euscara et division en dialectes, sous dialectes et variétés. Londres: Stanford's Geographical Stablishment). Por otra parte, autores naturales y residentes en Tudela, ciudad al sur de los límites meridionales de la lengua vasca en 1587 (Cfr. Lecuona, M. 1966. "El euskera en Navarra a fines del siglo XVI", en Geografía Histórica de la lengua vasca (siglos XVI-XIX): 127-137. San Sebastián: Auñamendi; Irigaray, A. 1966. "Documentos para la geografía lingüística de Navarra", en Geografía Histórica de la lengua vasca (siglos XVI-XIX): 67-103. San Sebastián: Auñamendi; Jimeno Jurío, J. M. 1987. Navarra. Historia del euskera. Tafalla: Txalaparta), manifestaron un convencido vascocantabrismo. Ya hemos hablado más arriba del historiador Pedro de Agramont. Muchos años más tarde, pasada ya la gran marea cantabrista, otro tudelano, el dramaturgo neoclásico Cristóbal Cortes y Vitas aparece en el informe que realizó a instancias de la Diputación navarra en 1790 en relación con un Epítome de la Historia de Navarra escrito por Manuel de Ynca Yupanqui como un seguidor radical del apologético discurso cantabrista de Moret en dos párrafos. En el primero, afirma esto: "La región de los Vascones llamados después navarros vivió siempre con particular independencia. Si Gutiérrez Coronel Autor de los Soberanos de Castilla se esfuerza a provar esta continua libertad en aquella provincia, no son menores los fundamentos, con que pueden establecerla los Vascones. Hasta Augusto no se especifica guerra formal, y directa contra ellos; todas son pasageras, y por ocasión, que no alteran la forma de su govierno. Moret (folio 16) dice, que Augusto tuvo por mengua del imperio Romano, que después de doscientos años, que harían en España conquistar sus armas, huviese regiones, que no reconociesen su señorío; y una de éstas fue sin duda alguna la de los Vascones". En el segundo párrafo sostiene lo siguiente: "Aún después de la guerra de Augusto dirigida más precisamente contra los Cántabros, como lo demuestra el sitio en que estuvo la fuerza de ella; no suena movimiento, o mudanza de gobierno en los Vascones, bien que se dice allanada toda España. Éstos conservan su lengua, por más que los Romanos avían introducido la suya en todo lo que conquistaron en España, prueva nada equívoca de aver sido pasagera la dominación, o sólo honoraria como el que se pone bajo la protección de otro soberano sin pérdida de su libertad, y gobierno". AGN, Reino, Sección de Historia, literatura..., legajo 3, carpeta 11: Censura dada con encargo de la Diputación del Reino por don Cristóbal María Cortés vecino de 
Hualde se hace partícipe de las tesis cantabristas, según las cuales "la Cantabria comprendía a la Navarra", "entendiendo a la Cantabria en toda su extensión, y sin la diferencia de antigua y moderna, especie en que no es del caso por ahora hacer materia de discusión". Para ello menciona el Theatrum honoris de Pedro González de Salcedo (Madrid, 1672). En apoyo de la formulación tubalista menciona curiosamente a diversos autores aragoneses como "Aynsa en su fundación, excelencias \& de Huesca, impreso en ella en 1619" y la obra Gloria de Tarazona (Madrid, 1708). Su cantabrismo y su tubalismo lo enlaza con la impureza de las poblaciones allende del Ebro. Tras repasar todas "las naciones que sucesivamente ocuparon el suelo Español", que "eran todavía en mayor número de lo que suena y se aprehende", Hualde deduce que más allá de Navarra y de Vascongadas "los primitivos originarios Españoles, comparados con aquel diluvio de bárbaros, que dominaron tantos siglos antes y después de la venida de nuestro Redentor, serían como algunas gotas no más de otro precioso licor destiladas en un estanque de agua, o en un caudaloso río, y aún éstos llenos de inmundicia", no pudiéndose concebir que en los "Reynos y Provincias señoreadas por aquellos salteadores, vandoleros, y forajidos, con los quales libremente, o forzados no pudieron menos de mezclarse en tanto grado, pueda extraerse una gota, por mínima que sea, de la primitiva y pura sangre Española, sangre que transmitieron los Patriarcas, y fundadores de nuestra población; es decir, la qual no esté infecta con aquella peste sin medida". Por el contrario, en relación con "los Navarros y regiones Vascongadas", "por la razón contraria, o inversa; si hablamos, como supongo de la sangre castiza, no es posible hallar algún destello, ni la mínima partícula, que no sea pura y limpia de semejantes razas; de contagio semejante".

En su argumentario no se olvida de los godos ni de aquéllos que presumen descender de sangre visigótica. Citando los comentarios de Luis Vives a la Ciudad de Dios de San Agustín aduce que "los tales Godos fueron a lo menos pérfidos, traidores, alevosos, infieles a su Señor, y perjuros, y hereges Arrianos, tales que carta semejante no se vió en el mundo en todas sus circunstancias. ¿Puede ser gloria el descender de ellos?. Parece afrenta, vilipendio, infamia".

\section{EL INFLUJO DE RISCO EN TRAGGIA.}

Unos años más tarde, los mismos propósitos que animaron a Risco motivarían a Joaquín Traggia Uribarri en el artículo que redactó sobre

Tudela al Epítome de la historia de Navarra escrito por don Manuel de Ynca Yupanqui preso en la ciudadela de Pamplona. resulta de las contestaciones que no se adoptó la obra y que la Diputación deseaba se encargase de escribirla el mismo Cortés (1790). 


\section{LA VASCONIA DE MANUEL RISCO Y LA POLÉMICA SUBSIGUIENTE 329 SOBRE EL PASADO DE NAVARRA}

Navarra en los dos primeros y únicos volúmenes, los dedicados a los cuatro territorios vascopeninsulares, del Diccionario geográfico-histórico de España publicado por la Real Academia de la Historia en 1802, un proyecto ideado e impulsado desde hacía varias décadas atrás precisamente por Campomanes. ${ }^{79}$ No obstante, su discurso se diferenciaría netamente del de aquél, tanto en el contenido como por el espacio cronológico que abarca.

Traggia, nacido en Zaragoza en 1748 y fallecido en Madrid en 1802, entró en la orden de los escolapios, residiendo como sacerdote varios años en Filipinas y llegando a redactar una gramática de tagalo. Regresó a España en 1772 y trabajó en los establecimientos educativos de su orden en Valencia, Zaragoza y Madrid, alternando las clases con su labor literaria e histórica. Se secularizó en 1794. Ingresó en la Real Academia de la Historia el 2 de septiembre de 1791, desde donde pudo entregarse del todo a su quehacer historiográfico como bibliotecario y anticuario de la institución. Su obra fue muy vasta, cultivando numerosas disciplinas. Con todo, sus obras principales tienen que ver con la historia de Aragón, tales como el Aparato de Historia Eclesiástica de Aragón (Madrid, t. I, 1791, y t. II, 1792); la Memoria para ilustrar el reinado de Ramiro II el Monje (Madrid, 1799); el Discurso sobre el origen y sucesión del Reino Pirenaico (Madrid, 1802); y la Memoria sobre el origen del Condado de Ribagorza (Madrid, 1817).

El primer empeño de Traggia en su artículo sobre Navarra en el mencionado Diccionario es, al igual que sucedía con Risco, rebatir el discurso historiográfico de los historiadores navarros de la Edad Moderna de presentar, por medio de la asunción de las tesis cantabristas y tubalistas, a los navarros como los genuinos españoles y a los visigodos como usurpadores extranjeros, con lo que se refutaban las posiciones de quienes derivaban la legitimidad de los Habsburgo hasta 1700, y de los Borbones desde esa fecha, de la continuidad dinástica presumida entre la estirpe gótica, la asturiana y la castellanoleonesa. ${ }^{80}$

${ }^{79}$ Acerca de la historia y pormenores de la iniciativa, veáse Manso Porto, C. 2005. "El Diccionario geográfico-histórico de la Real Academia de la Historia". Iura Vasconiae 2: 281-332.

${ }^{80}$ Acerca de si esa finalidad de acoso a las estructuras discursivas e historiográficas de los regímenes forales pudiera ser la razón de ser fundamental de los tomos del Diccionario de 1802 dedicados a Vascongadas y Navarra, Gregorio Monreal Zia (2005. "Posibles motivaciones, modus operandi y autores y colaboradores del Diccionario", en Diccionario geográfico-histórico de España por la Real Academia de la Historia: Sección I, comprehende el Reyno de Navarra, Señorío de Vizcaya y provincias de Álava y Guipúzcoa, 1802: 22. San Sebastián. Edición digital editada por la Fundación para el Estudio del Derecho Histórico y Autonómico de Vasconia) ha señalado que en la iniciativa se mezclaban la "pura empresa o aventura historiográfica" y el 
Siguiendo a Pellicer, Traggia afirma fantasiosamente y sin aportar ningún argumento digno de crédito, que los navarros serían un pueblo godo establecido en la época de Suintila y Wamba en la Zona Media y en la Ribera de Navarra que, con el tiempo, se habrían fusionado con los originarios pobladores vascos del territorio. De paso, sugiere que los reyes visigodos habrían imperado en Navarra, a partir de Wamba con carácter más o menos definitivo y hasta él, eventualmente, con reyes como Suintila. De forma paralela, rechaza de plano el tubalismo y remarca que no hay ninguna prueba de ello. A su juicio, "Los escritores de las cosas de Navarra han tenido la vanidad que los de las otras provincias, queriendo que su país fuera el primero ó de los primeros que pobló Tubal. Mas ni de la venida de éste patriarca, ni de la de sus hijos hay mas prueba que discursos voluntarios sobre un texto dudoso de Josefo, autor muy distante de aquel tiempo para hacer fe; y la libre interpretación de Rufino y de otros autores. Nada se sabe de lo acaecido en Navarra antes del arribo de los cartagineses a España, y nada se puede afirmar ni de los primeros pobladores, ni de la religión, usos, leyes y hechos de sus descendientes".

Sin embargo, en relación con la mayor o menor antigüedad del reino navarro en comparación con el asturiano, Traggia rechaza documentalmente "la pretension moderna de algunos escritores, que quieren que en los principios de la restauracion, Navarra fué parte del reyno de Asturias, y del imperio de los francos" y muestra el surgimiento plenamente independiente de la monarquía pirenaica.

En lo concerniente a la erección del primer monarca, Traggia rechaza, en cambio, la narración de varios cronistas, como el Príncipe de Viana y Dávalos de la Piscina, según la cual una docena de ricoshombres habrían decidido consultar al Papa, a los longobardos y a los francos "para establecer con su consejo la forma de gobierno que mas les cumpliese". Apoyándose en autores aragoneses, Traggia mantiene que la elección de rey se hizo sin ninguna asesoría externa y que previamente a ello se establecieron "las condiciones con que debía recibir la corona el electo, y que jurase su observancia antes de ser proclamado" con el fin de evitar "la arbitrariedad en los negocios graves, y la opresion de los vasallos". Traggia añade que se obligó "al príncipe

\footnotetext{
"trabajo pragmático sugerido desde los aledaños o el centro mismo del poder". Téngase en cuenta que las tensiones crecientes entre los cuatro territorios y la administración central habían ido in crescendo en las últimas décadas del siglo XVIII, llegándose a su punto más alto en la Guerra de la Convención y en el posterior ataque emprendido por Godoy contra los regímenes forales. En relación con las diferencias entre Navarra y el gobierno central, veáse el trabajo clásico de Rodriguez Garrraza, R. 1974. Tensiones de Navarra con la Administración central (1778-1808). Pamplona, Diputación Foral de Navarra/CSIC.
} 


\section{LA VASCONIA DE MANUEL RISCO Y LA POLÉMICA SUBSIGUIENTE 331 SOBRE EL PASADO DE NAVARRA}

con la religion del juramento á no emprender cosa alguna de entidad sin el consejo y voluntad de los ricos hombres" y que la formulación de "estos pactos, que no se escribieron por entonces" se fundamentó solamente en "el código antiguo de los godos [el Fuero Juzgo], sin recurrir a países extranjeros". Esas tesis se repiten al hablar de la legislación de Navarra, comentando Traggia que "despues de muchos debates entre los señores y antes de pasar a elegir rey y caudillo, se establecieron algunas leyes fundamentales para templar la autoridad del futuro señor y dexar al súbdito expedito el recurso a las leyes contra qualquier abuso de poder", surgiendo "este pensamiento (...) a lo que racionalmente se puede inferir, del Fuero Juzgo". Con esas bases surgió la constitución pirenaica: "Sin renunciar, pues, a sus usos municipales, sin abandonar el Fuero Juzgo, en cuyo lugar no hubieran sabido substituir otro tolerable, elígieron rey, obligándole ántes á jurar que les conservaria sus fueros, que nada resolveria de grave sin el consejo de los ancianos; que los empleos y presas serían para los vasallos; y que éstos tendrían expedito el recurso de las leyes en caso de opresion y violencia".

Por lo tanto, si bien Traggia aceptaba en líneas generales el discurso tradicional de los navarros sobre el origen del reino de "libertad de los nobles navarros que deciden elegir un rey y con carácter previo establecen una serie de leyes fundamentales que el nuevo rey debe jurar", no asumía "el relato del prólogo del Fuero General con la apelación al Papa y a otros pueblos extranjeros" y "de acuerdo con su tesis del origen godo de los navarros, defendía además la vigencia del Fuero Juzgo en el reino de Navarra" lo que "contribuía a rebajar la particularidad del derecho navarro y a aproximarlo al régimen jurídico vigente en Castilla". ${ }^{81}$

Más adelante, en ese apartado dedicado a la legislación de Navarra se habla del desarrollo normativo en ese territorio. Hasta muchos siglos después, no se establecieron leyes generales: a causa del "poco ocio y poca aptitud de los que podían pensar", "cada pueblo y distrito se gobernaba por sus usos y por los fueros particulares que les concedían los príncipes, acomodados al interes presente y privado". A pesar de que las contradicciones entre esos fueros locales se iban resolviendo puntualmente conforme se hacían aquéllas evidentes, hasta el año 1237, con Teobaldo I, no se recogerían por escrito las leyes navarras, con la redacción del Fuero General por medio de una comisión al efecto, a causa de las discrepancias registradas en la Cortes de Estella de aquel año "sobre la inteligencia de los fueros entre los letrados del príncipe y los del reyno". Según Traggia, ese Fuero General se ha mantenido en Navarra "sin alteracion substancial hasta el día de hoy",

${ }^{81}$ García Pérez, R. D. 2008: 307-308. 
consistiendo esencialmente en dos puntos principales, el primero, "que la potestad legislativa reside radicalmente en las córtes ò junta de los estados, que representan el reyno", y el segundo, que "el rey sin voluntad de los ricos hombres (...), no podía hacer hecho alguno granado". Para el escolapio aragonés, "en virtud de este reglamento fueron siempre los navarros libres de toda contribucion, exaccion ó impuesto, que no se hiciese á voluntad y consintiendo en ello los tres estados que formaban las cortes". Con todo, al pasar la frontera de 1512, Traggia introduce una novedad importante: a su juicio, "la incorporacion con Castilla (...) como que no fué por el derecho de sucesion, ni por llamamiento de los estados, sino por las armas y conquista, pudo alterar la constitucion de Navarra. Sin embargo el rey católico D. Fernando y sus sucesores hasta el día, la han mantenido por sí y por sus vireyes sin alteracion substancial, en virtud del juramento que libre y espontáneamente han prestado por considerarlo así útil y conveniente al bien general, que es la ley suprema de los estados, y la única, imprescriptible é invariable en ellos, si se quieren conservar". Es decir, en conformidad con todo ello, los fueros navarros dependerían exclusivamente de la voluntad del monarca y de su aquiescencia de cara a mantenerlos. Si bien hasta la conquista de 1512, los reyes navarros "fueron verdaderamente constitucionales y obligados ad pacta conventa", en cuanto que obligados al pacto constitucional suscrito inicialmente con la elección del primer monarca, y renovado posteriormente por sus sucesores, a partir de entonces se abre una etapa "que puede llamarse de privilegio, supuesto que el rey católico $y$ sus sucesores han conservado substancialmente su antigua constitucion, á pesar de que la privacion de Juan de Labrit y la fuerza de las armas le abriéron el camino para la posesion de la corona de Pamplona. No habiendo llamado los navarros al rey católico, y careciendo de fuerzas para sostener sus leyes, admitieron al exército del rey despues de una ligera resistencia, y baxo las condiciones que éste tuvo a bien otorgarles por su beneficencia, y por creerlas útiles al bien del estado, rechazando las que no le pareciéron convenientes. Así la obligacion que hacen los reyes es voluntaria en su raíz, y voluntario su juramento, y no nacido de otra causa extraña que precise a su observancia".

Esa tesis de que la pervivencia del derecho y de las instituciones propias había sido, según Traggia, concesión graciosa del rey "dejaba al reino, desde un punto de vista jurídico, bastante desprotegido, pues la capacidad de vincular la potestad soberana del privilegio era notoriamente inferior a la del pacto. Éste segundo, en virtud de la doctrina jurídica tradicional, pero también en el contexto de los nuevos principios voluntaristas, que tendían a liberar la soberanía de cualquier ligamen ajeno a ella, presentaba una virtualidad notoriamente superior al privilegio -figura ésta última cada vez más odiosa-, en la construcción de un discurso jurídico conservador o actualizador de las libertades 


\section{LA VASCONIA DE MANUEL RISCO Y LA POLÉMICA SUBSIGUIENTE 333 SOBRE EL PASADO DE NAVARRA}

tradicionales". Por otra parte, al ser una concesión graciosa, realizada en atención al bien general, consideraciones de igual género podían en el futuro sugerir la revocación de la constitución del reino. ${ }^{82}$ Esas tesis serán unos años más tarde retomadas por José María de Zuaznávar y Francia en la segunda edición del Ensayo Histórico-Crítico sobre la Legislación de la Navarra (San Sebastián, 1827-1829). ${ }^{83}$

Al igual que sucedió con Risco, la reacción de las instituciones navarras a las interpretaciones de Traggia fue de una tibieza ininteligible. Tan pronto como recibió la obra, la Diputación escribió al historiador aragonés el 14 de mayo de 1802 comunicándole "el distinguido aprecio que le merecen sus desvelos". No obstante, seguidamente le transmitía "que en la rápida lectura que a hecho del artículo de Navarra a observado ciertas claúsulas que le precisan a entregarse con alguna detención a reflexionarlas; y que practicada esta diligencia trasladará a sus manos el resultado de ellas, no dudando de la acreditada sinceridad de V. y amor a la fidelidad de la Historia se servirá estimar esta previa diligencia como fruto de su obligación y del activo deseo que deve animarle de que un monumento tan digno por todos respetos de la luz pública, no derogue o disminuia a este privilegiado País los justos derechos de su constitución, en aquel o aquellos periodos que puedan ofenderla contra las rectas intenciones de v.". ${ }^{84}$

Un año más tarde, por efecto de la correspondencia mantenida con la Diputación alavesa, la Diputación se mostrará algo más tajante, pero sin que ello se sustanciara en reacción alguna. La institución alavesa había encontrado en el Diccionario de 1802 "ciertas expresiones y noticias equivocadas (...) tratando de ilusión, preocupación y ceguedad la idea de su livertad e independencia ahun antes de su voluntaria

82 Ibidem: 308-310.

83 Un análisis de esa obra en Leoné Puncel, S. 2005: 206-218 y en Mikelarena Peña, F. 2012. "La refutación absolutista del discurso pactista navarro: José Maria de Zuaznavar y Francia y el Ensayo histórico-crítico sobre la legislación de Navarra". Cuadernos de Historia del Derecho, en prensa.

${ }^{4}$ AGN, Reino, Sección de Historia, Literatura, Legajo 3, Carpeta 19 (1802). No obstante, quien tenía que entregar la carta a Traggia, un navarro residente en Madrid, Martín Antonio de Huici, escribió a la Diputación haciendo constar la escasa ayuda que los redactores del Diccionario habían recibido tanto de la misma Diputación como de particulares navarros y atribuía, erróneamente a nuestro entender, a esa falta de colaboración los errores detectados. Con todo, Huici hablaba también de las responsabilidades de los navarros y de la Diputación al comentar que "nuestros paisanos no toman el interés que otros en estas cosas; y no sería de maravillar que los artículos de nuestro Reyno sean los más inexactos de todos, y que se quede sin perfeccionar, si esa Diputación no piensa en hacer un trabajo que sea digno de ella". 
entrega al Rey Don Alonso el Xl" y había encargado "a sus Asesores y otros Literatos el examen de esta materia a fin de que con vista de documentos, y demás noticias conducentes recopilen quanto pueda servir para desvanecer las ideas indicadas y fundadas en principios mal entendidos y contrarios a las glorias constantes de esta Provincia". Además, la Diputación alavesa consideraba que la Diputación navarra debía "considerarse igualmente agraviado en ellas" y le planteaba una acción conjunta acerca de la materia mencionada. ${ }^{85}$ La institución navarra respondió que le parecía "justo y muy propio", sobre todo, por las analogías entre ambos territorios "así en el ejercicio de sus regalías, como en los títulos directos devidos a un formal y solemne contrato jurado al tiempo de la elección de su primer Soberano, y continuado por todos los Señores Reyes sus sucesores" ${ }^{86}$ Con todo, la corporación navarra no impulsaría ninguna iniciativa.

\section{BIBLIOGRAFÍA}

Aranzadi, J. 1981. Milenarismo vasco. Edad de oro, etnia y nativismo. Madrid: Taurus.

Bonaparte, L. L. 1863. Carte des septs provinces basques mostrant la délimitation actuelle de l'euscara et division en dialectes, sous dialectes et variétés. Londres: Stanford's Geographical Stablishment.

Canellas López, A. 1979. "Los estudios paleográficos en España y el archivero Don Juan Antonio Fernández", en Palaeographica, Diplomatica et Archivistica. Studi in Onore di Giulio Battelli: v. II, 616- 633. Roma, Edizioni di Storia e Letteratura.

Caro Baroja, J. 1972. Los vascos y la historia a través de Garibay (Ensayo de biografía antropológica). San Sebastián: Txertoa.

Castro Álava, J. R. 1941. "Figuras tudelanas: Juan Antonio Fernández, Archivero de la Orden de Santiago". Revista Príncipe de Viana 2: 95-122.

- 1963. Autores e impresores tudelanos. Pamplona, Institución Príncipe de Viana.

- 1974. Juan Antonio Fernández: un tudelano del siglo de la llustración. Pamplona, Diputación Foral de Navarra-Dirección de Turismo, Bibliotecas y Cultura Popular. (1803).

${ }^{85}$ AGN, Reino, Sección de Historia, Literatura..., Legajo 3, Carpeta 21 ${ }^{86}$ Ibidem. 


\section{LA VASCONIA DE MANUEL RISCO Y LA POLÉMICA SUBSIGUIENTE 335 SOBRE EL PASADO DE NAVARRA}

Coronas González, S. M. 2002. “Estudio Preliminar”, en P. Rodriguez Campomanes, Inéditos políticos. Oviedo: Junta General del Principado de Asturias.

De Castro, C. 1996. Campomanes. Estado y reformismo ilustrado. Madrid: Alianza.

Fernández Albadalejo, P. 1975. La crisis del Antiguo Régimen en Guipúzcoa. Cambio económico e Historia, 1766-1833. Madrid: Akal.

Flórez, E. 1768. La Cantabria. Disertación sobre el sitio, y extensión que tuvo en tiempo de los romanos la región de los Cántabros, con noticia de las Regiones confinantes, y de varias poblaciones antiguas: discurso preliminar al tomo XXIV de la España Sagrada sobre la provincia de la Tarraconense: Madrid, Por Antonio Marín.

Floristán Imízcoz, A. 1991. La Monarquía Española y el Gobierno del Reino de Navarra, 1512-1808. Pamplona: Gobierno de Navarra.

- 1998. "Reflexiones sobre una identidad nacional a mediados del siglo XVI. Los orígenes del reino de Navarra", en Mito y realidad en la Historia de Navarra. Actas del IV Congreso de Historia de Navarra: 29-42. Pamplona: Sociedad de Estudios Históricos de Navarra, Volumen II.

- 1999. “¿Conquista o restauración?. La incorporación de Navarra a la monarquía española”, Hispania LIX/2: 457-491.

- 1999. Lealtad y patriotismo tras la conquista de Navarra. El licenciado Reta y la "Sumaria relación de los apellidos". Pamplona: Gobierno de Navarra.

- 2000. "Examen de la conquista castellana. La introspección de los cronistas navarros (siglos XVI-XVIII)". Príncipe de Viana 219: 79-134.

- 2004. "Ex hostibus et in hostes. La configuración de las identidades colectivas como confrontación múltiple: Navarra entre Sobrarbe y Cantabria (siglos XVII y XVIII)", en García García, B. J. y Álvarez-Ossorio Alvarino, A., coords., La monarquía de las naciones: patria, nación y naturaleza en la monarquía de Espana: 327-354. Madrid: Fundación Carlos de Amberes.

Fuentes Pascual, F. 1955. "Más sobre Juan Antonio Fernández". Revista Príncipe de Viana 59: 203-234.

García Pérez, R. D. 2008. Antes leyes que reyes. Cultura jurídica y constitución política en la Edad Moderna (Navarra, 1512-1808). Milano: Giuffrè Editore.

Goyhenetche, J. 1993. Les basques et leur histoire. Mythes et realités. Bayona-Donostia: Elkar. 
Irigaray, A. 1966. "Documentos para la geografía lingüística de Navarra", en Geografía Histórica de la lengua vasca (siglos XVI-XIX): 67-103. San Sebastián: Auñamendi.

Jimeno Aranguren, R. 2011. "Pedro Abarca y su tratado manuscrito $<$ Origen y progresos de la contienda sobre los primeros reyes de Aragón y Navarra , llamados de Sobrarbe>> (c. 1685)", Pedralbes, 31: 91-123. Txalaparta.

Jimeno Jurío, J. M. 1987. Navarra. Historia del euskera. Tafalla:

Juaristi, J. 1992. Vestigios de Babel. Para una arqueología de los nacionalismos españoles. Madrid: Siglo XXI.

Larrañaga Elorza, K. 1998. "Cantabrismo en Navarra”. Príncipe de Viana 214: 447-482.

Lecuona, M. 1966. "El euskera en Navarra a fines del siglo XVI", en Geografía Histórica de la lengua vasca (siglos XVI-XIX): 127-137. San Sebastián: Auñamendi.

Leoné Puncel, S. 2005. Los Fueros de Navarra como lugar de la memoria. San Sebastián: Fundación para el Estudio del Derecho Histórico y Autonómico de Vasconia.

Llombart, V. 1992. Campomanes, Economista y político de Carlos III. Madrid: Alianza Universidad.

Madariaga Orbea, J. 2008. Apologistas y detractores de la lengua vasca. San Sebastián: Fundación para el Estudio del Derecho Histórico y Autonómico de Vasconia.

Manso Porto, C. 2005. "El Diccionario geográfico-histórico de la Real Academia de la Historia". Iura Vasconiae 2: 281-332.

Mañaricua, A. E. 1971. Historiografía de Vizcaya (desde Lope García de Salazar a Labayru). Bilbao: LaGran Enciclopedia Vasca.

Martínez Gorriarán, C. 1993. Casa, provincia, rey (Para una historia de la cultura del poder en el País Vasco). Ensayo. San Sebastián: Alberdania.

Merino, A. y De la Canal, J. 1819. España Sagrada. Tomo XLIII. Tratado LXXXI de la Santa Iglesia de Gerona en su estado antiguo. Madrid: En la imprenta de Collado.

Mikelarena Peña, F. 2006. "Los manuscritos de la biblioteca de Juan Antonio Fernández, erudito tudelano". Príncipe de Viana 237: 273-299; 


\section{LA VASCONIA DE MANUEL RISCO Y LA POLÉMICA SUBSIGUIENTE 337 SOBRE EL PASADO DE NAVARRA}

- 2008. "Los libros de historia de la biblioteca de Juan Antonio Fernández, erudito tudelano y académico correspondiente de la RAH". Príncipe de Viana 244: 459-495.

- 2011. "La refutación absolutista del discurso pactista navarro: José Maria de Zuaznavar y Francia y el Ensayo histórico-crítico sobre la legislación de Navarra". Cuadernos de Historia del Derecho 18: 241-267

Monreal Zia, G. 2005. "Posibles motivaciones, modus operandi y autores y colaboradores del Diccionario", en Diccionario geográfico-histórico de España por la Real Academia de la Historia: Sección I, comprehende el Reyno de Navarra, Señorío de Vizcaya y provincias de Álava y Guipúzcoa, 1802: 19-23. San Sebastián: Edición digital editada por la Fundación para el Estudio del Derecho Histórico y Autonómico de Vasconia. Txertoa.

Otazu, A. 1973. El igualitarismo vasco: mito y realidad. San Sebastián:

Ozaeta y Gallaiztegui, J. H. 1779. La Cantabria vindicada y demostrada, según la extensión que tuvo en diferentes tiempos. Madrid: En la oficina de Pedro Marín.

Pérez Goyena, A. 1947-1964. Ensayo de bibliografía navarra: desde la creación de la imprenta en Pamplona hasta el año 1910. Burgos: Imprenta Aldecoa, 9 volúmenes.

Risco, M. 1779. España Sagrada. Tomo XXXII. La Vasconia. Tratado preliminar a las santas iglesias de Calahorra, $y$ de Pamplona: en que se establecen todas las antigüedades civiles concernientes a la región de los Vascones desde los tiempos primitivos hasta los Reyes primeros de Navarra: 3v. Madrid: En la imprenta de Miguel Escribano.

- 1779. El R. P. M. Fr. Henrique Flórez vindicado del Vindicador de la Cantabria, Don Hipolyto de Ozaeta y Gallaiztegui. Madrid: En la Imprenta de Pedro Marín.

Rodriguez Garrraza, R. 1974. Tensiones de Navarra con la Administración central (1778-1808). Pamplona, Diputación Foral de Navarra/CSIC.

Sáinz y Pérez de Laborda, M. 1913. Apuntes Tudelanos. Tudela.

Tovar, A. 1980. Mitología e ideología sobre la lengua vasca. Historia de los estudios sobre ella. Madrid: Alianza.

Vallejo García-Hevia, J. M. 1997. La monarquía y un ministro, Campomanes: 21-45. Madrid: Centro de Estudios Políticos y Constitucionales. 